\title{
El regreso a la escuela: evidencias para México*
}

\author{
Guadalupe Fabiola Pérez Baleón** \\ David Philip Lindstrom***
}

El regreso a la escuela es una transición que forma parte de las trayectorias escolares de una parte de la población mexicana. Puede ser un punto de inflexión en la vida de las personas y una estrategia de avance socioeconómico. Los factores positivamente asociados con este retorno son: ser joven, tener una escolaridad previa de secundaria o más, no estar casado, haber vivido en zonas urbanas, tener experiencia migratoria previa, tener padres profesionistas o que se dediquen a actividades no manuales y pertenecer a cohortes jóvenes. Hay algunas diferencias en las tendencias del retorno por género que se pueden explicar por la influencia de los roles tradicionales.

Palabras clave: trayectorias escolares, transiciones, retorno educativo.

Fecha de recepción: 1 de octubre de 2012.

Fecha de aceptación: 13 de noviembre de 2013.

\section{Back to School. Evidence for Mexico}

Going back to school is a transition that forms part of the study background of part of the Mexican population. It can be a turning point in people's lives and a strategy for socio-economic advancement. Factors positively associated with this return include: being young, having previous schooling up to junior high school or over, not being married, having lived in urban areas, having previous migratory experience, having professional parents engaged in non-manual activities and belonging to younger cohorts. There are certain differences in return trends by gender that can be explained by the influence of traditional roles.

Key words: study background, transitions, re-entry into education.

* La autora agradece a la Universidad Autónoma Metropolitana-Xochimilco la beca posdoctoral que le otorgó durante la elaboración de este artículo.

** Posdoctorante en la Universidad Autónoma Metropolitana-Xochimilco, División de Ciencias Sociales y Humanidades, Maestría en Estudios de la Mujer. Dirección postal: Calzada del Hueso 1100, col. Villa Quietud, delegación Coyoacán, C.P. 04960, México, D.F., México. Correo electrónico: <gfperez@correo.xoc.uam.mx> y <ggfabiola@hotmail. com>.

*** Brown University, Department of Sociology Population Studies and Training Center. Dirección postal: 68Waterman St., Providence, RI 02912, Estados Unidos. Correo electrónico:<david_lindstrom@brown.edu>.

$\overline{\text { ESTUDIOS DEMOGRÁFICOS Y URBANOS, VOL. 29, NÚM. } 3 \text { (87), 2014, 579-619 }}$ 


\section{Introducción}

La educación formal es considerada como una inversión en capital humano que permite a las personas adquirir no sólo conocimientos útiles para la vida y aspirar a un trabajo bien remunerado, sino también insertarse en redes sociales y culturales que enriquezcan su vida individual y familiar y promuevan la movilidad social.

Miller (2007 y 2009) conceptualiza a la escolarización como un proceso compuesto por diversas etapas que en conjunto constituyen un continuum llamado "trayectoria escolar", la cual está conformada por varias transiciones: ingresos, salidas, reingresos y cambios de nivel escolar, enmarcadas en ciclos o etapas y desarrolladas simultáneamente en contextos biográficos más amplios y complejos tales como el entorno familiar, cultural y económico del individuo.

En este tenor, existen transiciones de las trayectorias escolares que han sido poco estudiadas. En concreto, hay un vacío en el conocimiento sobre el fenómeno de la reinserción educativa de aquellas personas que una vez fuera del sistema escolar deciden regresar a la escuela en un intento por concluir los estudios que dejaron truncados o para continuar incrementando su nivel educativo. Lo anterior se debe en parte a la ausencia de fuentes de información que contengan datos longitudinales que documenten esta situación. Al respecto, la Encuesta Demográfica Retrospectiva (Eder), realizada en 1998, es la primera en recolectar información retrospectiva sobre educación para una muestra representativa a nivel nacional, lo que ha permitido realizar este tipo de análisis.

El objetivo de este artículo es describir las características de los hombres y las mujeres de tres cohortes de nacimiento ${ }^{1}$ que habiendo dejado la escuela regresaron a ella en algún momento en su vida, para compararlas con las de aquellos que teniendo características similares no retornaron al sistema escolar, así como precisar los factores asociados a dicho retorno a fin de contribuir a incrementar el conocimiento existente sobre el tema.

Esta investigación se inscribe dentro del enfoque del curso de vida y la teoría del capital humano. Por medio de estas teorías se generaron hipótesis sobre los determinantes que llevan a hombres y mujeres mexicanos a regresar a la escuela. La teoría del capital humano destaca el papel que tiene la educación en la mejora de las competencias y

\footnotetext{
${ }^{1}$ Las cohortes son: 1936-1938, 1951-1953 y 1966-1968.
} 
en la productividad, las cuales a su vez son recompensadas en el lugar de trabajo con mayores ingresos económicos.

Por su parte, el curso de vida retoma el concepto de las trayectorias educativas, las cuales, más que como una línea ininterrumpida, pueden ser vistas como secuencias compuestas de ingresos tempranos o tardíos a la escuela y de posibles reprobaciones, rezagos, salidas y regresos a la misma.

El trabajo está dividido en tres partes: en la primera se presentan los antecedentes históricos y teóricos sobre el tema; en un segundo apartado se realiza un análisis descriptivo en donde se comparan las características promedio de la población que retomó sus estudios con las de aquella que no regresó; en la tercera parte se precisan los factores sociodemográficos que afectaron dicho retorno, para lo cual se emplean modelos logísticos de tiempo discreto.

\section{La educación en México}

La educación tiene primordial relevancia en el desarrollo de todo país; sin embargo, durante el siglo pasado los indicadores educativos de México no fueron del todo alentadores, a pesar de haberse presentado importantes avances. Por una parte el analfabetismo disminuyó al pasar de 54\% en 1940 a 9.5\% cerca del año 2000. No obstante fue bajo el número medio de años aprobados en la escuela, ya que pasó de 2.2 a 7.4 años entre 1940 y 1997 (Muñoz y Suárez, 1994; Parker y Pederzini, 2000; Tuirán y Zúñiga, 2000; Aboites, 2006; Giorguli, 2006; Greaves, 2011; Vázquez, 2011). ${ }^{2}$

Por lo que respecta a las cohortes en estudio, se han precisado importantes diferencias de género en la edad mediana de la salida de la escuela: las mujeres de la cohorte antigua la dejaron a los 12 años, mientras que su contraparte masculina lo hizo a los 12.9 años, en tanto que en la cohorte más joven esta edad se situó en 15.7 y 16.7 años respectivamente. Si bien aumentó con el tiempo la proporción de mujeres que obtuvieron niveles educativos más altos, esto fue más marcado para el caso de los varones, pues en todas las cohortes fueron quienes con mayor frecuencia lograron llegar a los niveles medio superior y superior (Pérez Baleón, 2012).

${ }^{2}$ El panorama educativo que aquí se considera abarca entre 1940 y finales de la década de los noventa, ya que entre esos años crecieron, se desarrollaron y fueron encuestadas las tres cohortes incluidas. 
En materia de escolaridad el México posrevolucionario se caracterizó por los rezagos abismales entre el campo y la ciudad, así como entre el campesinado, el sector obrero y ciertos grupos de la clase media, tanto en la distribución de las oportunidades de cursar la primaria completa ${ }^{3}$ como en la expansión de la enseñanza media y superior; se favorecieron más las zonas desarrolladas y menos las rezagadas, pues en las primeras se construyeron más y mejores recintos educativos de todos los niveles, se les destinaron mayores recursos y se pagaron a los docentes sueldos menos raquíticos. Todo ello hizo de la escuela un elemento adicional de marginación que aún hoy no se ha podido erradicar totalmente (Latapí, 1973; Greaves, 2011).

Los distintos gobiernos, junto con las autoridades educativas de la época, se abocaron principalmente a combatir el analfabetismo y a aumentar el número de personas con acceso a la primaria, y para ello ejecutaron diversas estrategias en distintos momentos del siglo XX. Entre ellas destacan el Plan de Once Años puesto en marcha en 1960 por Jaime Torres Bodet, ${ }^{4}$ y la promulgación de la ley de educación de 1973. ${ }^{5}$ Sin embargo, pese a los esfuerzos realizados fue hasta 1982 cuando se logró una cobertura nacional del $86 \%$ en el nivel de primaria, con una eficiencia terminal del 50.4\% (Vázquez, 2011).

Por su parte las escuelas secundarias, si bien en menor número que las primarias, fueron instaurándose en distintos momentos del siglo pasado. ${ }^{6}$ Para responder a las demandas de la época, entre 1964

\footnotetext{
${ }^{3}$ Por ejemplo, para 1940 la mayoría de las escuelas primarias rurales ofrecía como máximo tres grados de escolaridad, de manera que sólo cuatro de cada 100 niños inscritos en primer grado llegaban al sexto año, mientras que en las ciudades el $55 \%$ de las primarias tenían los seis grados (Greaves, 2011; Vázquez, 2011). Más de veinte años después el panorama no era muy diferente, pues en 1963 por cada 100 alumnos de primer ingreso en escuelas urbanas llegaban 44 al sexto grado, mientras que en la escuela rural sólo lo lograban cinco (Latapí, 1965).

${ }^{4}$ Los objetivos que planteaba el Plan de Once Años eran tres: 1) incorporar a la primaria a los niños que todavía no eran atendidos por falta de plazas escolares, 2) dotar de plazas a la educación para poder inscribir cada año a todos los niños de seis años y 3) mejorar la eficiencia terminal de la misma, de modo que el $38 \%$ de los niños que iniciaran su primaria en 1965 permanecieran en la escuela hasta matricularse en el sexto grado en 1970 (Latapí, 1965; Muñoz y Suárez, 1994; Carranza, 2004; Greaves, 2011).

${ }^{5}$ Con esta ley se reformaron los métodos, los programas de estudio y los libros de texto de primaria (Vázquez, 2011).

${ }^{6}$ Fue en 1923 cuando se creó en México el Departamento de escuelas secundarias, el cual tenía a su cargo en ese momento sólo cuatro planteles en todo el país. Su expansión fue lenta, ya que por entonces la prioridad era atender los problemas de cobertura en primaria, y además había serias discusiones acerca de cuáles debían ser el propósito y los currículos de la secundaria (Zorrilla, 2004).
} 
y 1970 se promovieron la creación y el crecimiento de las secundarias técnicas agropecuarias, industriales y pesqueras, así como de la telesecundaria. En los niveles medio y superior también se dieron pasos hacia el crecimiento: entre 1940 y 1946 se transformó el Instituto de Preparación del Magisterio de Segunda Enseñanza en la Escuela Normal Superior; en 1952 se inauguró la Ciudad Universitaria de la Universidad Nacional Autónoma de México (UNAM); en 1959 se pusieron en funcionamiento las instalaciones de Zacatenco del Instituto Politécnico Nacional (IPN); en 1971 se creó el Colegio de Ciencias y Humanidades (CCH); en 1973 se abrió el Colegio de Bachilleres; en 1974 se fundó la Universidad Autónoma Metropolitana (UAM); en 1978 se crearon el Colegio Nacional de Educación Profesional Técnica (Conalep) y la Universidad Pedagógica Nacional (UPN) (Carranza, 2004).

Con el propósito de acercar la educación formal a un mayor número de personas, y en reconocimiento a que no todas ellas cuentan con los medios económicos ni con el tiempo suficiente para cursar estudios en los sistemas escolarizados graduados por edad, a partir de la década de los setenta se dieron los primeros pasos para incorporar a estos alumnos a los distintos niveles de escolaridad. Para ello en 1974 se facilitó la revalidación de estudios y se reconoció la educación a distancia con el patrocinio de la UNAM. En 1979 la preparatoria abier$\mathrm{ta}^{7}$ inició formalmente su programa de estudios en todo el país, y a partir de 1984 se logró la cobertura nacional en México (Carranza, 2004).

En 1981 se fundó el Instituto Nacional para la Educación de los Adultos (INEA) ${ }^{8}$ para combatir el analfabetismo y el rezago educativo de la población mayor de 15 años que no había ingresado a la escuela primaria o secundaria a la edad reglamentaria, o que habiendo ingresado en tiempo y forma la había abandonado en algún momento sin haber concluido el nivel correspondiente, quedando así en condición de rezago educativo (Vázquez, 2011).

Además de estos cursos han surgido una gran variedad de programas de educación básica, media, superior y de capacitación, presenciales y a distancia -brindados por escuelas públicas y privadas- que

${ }^{7}$ La preparatoria abierta ofrece cursos no escolarizados, en donde el estudiante no necesariamente asiste a clases. Este sistema es comúnmente utilizado por personas que ya están laborando o que no concluyeron su educación media superior.

${ }^{8}$ Actualmente el INEA ofrece atención educativa a niños de 10 a 14 años sin primaria, así como a jóvenes mayores de 15 años y a personas adultas, a quienes brinda servicios educativos de alfabetización y educación primaria y secundaria en modalidades semiescolarizadas y abiertas. 
han ido multiplicando la oferta educativa. Es posible que muchas de las personas a las que se refiere este artículo hayan retomado sus estudios en tales programas, sin embargo la encuesta empleada no permite precisar con finura tales detalles, por lo que sólo se apunta esta posibilidad para tomarla en cuenta en futuros trabajos.

\section{Estado del arte en torno a la cuestión educativa}

En México las investigaciones sobre educación que han realizado los estudios de población se han orientado a observar las diferencias en la permanencia y en el desempeño escolar que logran las mujeres y los varones según su cohorte, su ámbito de socialización de procedencia (rural o urbano), su adscripción a un grupo étnico y su estrato socioeconómico (Ojeda, 1989; Parker y Pederzini, 2000; Camarena, 2000; Tuirán y Zúñiga, 2000; Mier y Terán y Rabell, 2000, 2001, 2002 y 2005; Giorguli, 2002; Echarri y Pérez Amador, 2003; Mier y Terán, 2004 y 2007; Polo Arnejo, 1999; Coubès y Zenteno, 2005; Castro y Gandini, 2006; De Oliveira y Mora, 2008 y 2011; Pérez Baleón, 2012).

Algunas se han enfocado en analizar las características del entorno familiar de los estudiantes, entre las que destacan el tipo de estructura familiar, los recursos del hogar, el tipo de jefatura, el sector social, la escolaridad y la ocupación del jefe de familia (Giorguli, 2002 y 2006; Mier y Terán y Rabell, 2001 y 2002), así como el lugar que los jóvenes ocupan dentro de su familia y el tamaño del hogar (Camarena, 2000; Mier y Terán y Rabell, 2002).

Otros trabajos dan cuenta del inicio de las trayectorias educativas, concretamente de la primera salida de la escuela y su articulación con el trabajo y/o con la unión conyugal (Quilodrán, 1996; Tuirán, 2002; Blanco, 2001 y 2002; Coubès y Zenteno, 2005; Guerra, 2008; Pérez Baleón, 2010).

Gracias a la existencia de bases de datos con que cuentan algunas universidades mexicanas como la UAM, se han podido realizar trabajos que analizan la deserción estudiantil de sus estudiantes (Durán y Díaz, 1999). Otros trabajos efectuados en la misma universidad articulan las trayectorias escolares con algunos otros eventos biográficos individuales, familiares y sociales, así como con sucesos "perturbadores" -tales como los divorcios de los padres y las huelgas universitarias- para analizar cómo éstos aceleran o retrasan la dirección y el sentido de las trayecto- 
rias escolares (Miller, 2007 y 2009). Se ha profundizado asimismo en el conocimiento de la trayectoria académica de algunos alumnos de la UNAM, poniendo énfasis en los factores asociados al egreso y al abandono, a fin de detectar oportunamente las características de la población universitaria en riesgo de desertar de su carrera (Millán, 2011).

Algunos estudios efectuados en otras áreas del conocimiento se han enfocado en el análisis de las trayectorias escolares de adolescentes y jóvenes desde diferentes aspectos. En ellos se reporta el promedio de escolaridad de los países, ya sea por sexo o por ingreso, así como la distribución de la población por niveles educativos (Dávila, 2002), y se busca definir conceptos como la deserción escolar, principalmente universitaria (Tinto, 1975; Nunes y Vieira, 2009).

En trabajos como los realizados por Terigi (2007) se distingue entre las trayectorias escolares reales y las teóricas. Esta autora afirma que las teóricas se encuentran expresadas en itinerarios progresivos, lineales, previsibles y con tiempos marcados por una periodización estándar, en tanto que las reales son vividas por los alumnos de modos heterogéneos, variables y contingentes dados por la selectividad que enfrentan al transitar de un nivel educativo a otro, ya que es común que gran número de jóvenes no se inscriba en el sistema escolar luego de haber concluido su nivel anterior. Además de ello, problemas como el ausentismo, las dificultades para aprender, el desfase con la edad de los compañeros de estudio, los rezagos, la reprobación, los abandonos temporales y los reingresos fallidos provocan que no todos los que se matriculan en un nivel y un grado específico lo concluyan, al menos no en tiempo y forma.

Investigaciones como las de Postigo y Daino (2006) y Santillán (2007) ponen el acento en la pobreza o en la desigualdad para analizar la importancia que el contexto o los actores sociales, tales como la escuela, las familias y el barrio, ejercen sobre las trayectorias educativas de los alumnos, ya que la deserción escolar puede ser considerada como un síntoma que refleja la escasez de recursos económicos de la población que la padece.

Pero aún faltan artículos que aborden las trayectorias escolares de las personas en el momento en que retoman sus estudios y emprenden una transición que puede ser considerada como un punto de inflexión ${ }^{9}$

${ }^{9}$ En inglés se le denomina turning points. Para evaluar los efectos de los puntos de inflexión se deben tomar en consideración la naturaleza de los eventos o transiciones, su severidad, los recursos, creencias y experiencias de las personas, así como las situaciones y los resultados surgidos de las alternativas disponibles (Elder, 1985). 
en su historia de vida al impulsarlas a redireccionar sus trayectorias educativas, laborales y familiares y el rumbo de la vida misma.

El reingreso escolar es un ejemplo de cómo los individuos continúan experimentando cambios fundamentales en distintas áreas vitales y están expuestos a adquirir nuevas pautas de conducta y a adoptar ideas y valores diferentes a los obtenidos en la primera parte de sus vidas, pautas que los llevarán a transformar su forma de pensar y de actuar dependiendo de sus circunstancias individuales y sociales y de sus motivaciones personales (Elder, Kirkpatrick y Crosnoe, 2003).

Hostetler (2008) considera que el regreso a la escuela es una transición clave del curso de vida, misma que debe ser entendida dentro del contexto de circunstancias personales pasadas y presentes del individuo. De esta manera, la decisión de retomar los estudios emerge de una mezcla particular de oportunidades, retos, metas y recursos, a la vez que sintetiza los senderos individuales, familiares y laborales del individuo, lo cual afecta su presente y su futuro.

La reinserción, como transición escolar, puede suceder en distintos casos y momentos de la vida, ya que algunas personas regresan a la escuela motivadas por el deseo de incrementar sus estudios o de especializarse en alguna área del conocimiento luego de haber concluido en una primera etapa su escolaridad objetivo, misma que es posible hayan logrado siguiendo un itinerario normativo en donde aprobaron un grado por año y cada nivel a tiempo.

Otras habrán vivido sus trayectorias escolares con eventos de rezago y reprobación sin que por ello abandonaran el sistema escolar, logrando finalizar sus estudios para tener la posibilidad de regresar a la escuela después de un tiempo fuera. Asimismo habrá casos en que las personas que dejaron inconclusa su escolaridad en algún punto de su trayecto formativo decidan volver posteriormente para concluirla.

Para algunas personas es importante regresar a la escuela ya que requieren actualizar habilidades que rápidamente se volvieron obsoletas en un mundo globalizado, o necesitan obtener documentos educativos que avalen sus conocimientos ante la solicitud de sus empleadores, o pretenden incrementar sus niveles de vida o se sienten insatisfechos con sus trabajos. Tales situaciones desdibujan la línea que separa las esferas educativas y las laborales y la idea de que éstas deben ser continuas y lineales (Hostetler, 2008). 


\section{El regreso a la escuela: el caso estadounidense}

A diferencia de México, en que la investigación sobre este tema es escasa, en países como Estados Unidos se ha realizado un gran número de estudios sobre el regreso escolar, ya que en las sociedades industrializadas como ésta, las personas no ven limitadas sus oportunidades de invertir en capital humano y en su entrenamiento a edades mayores, por lo que pueden regresar a la escuela en distintos momentos. Ello ha permitido que allí sea más común esta transición que en los países con menor desarrollo.

Los trabajos al respecto indican que la mayoría de quienes retoman sus estudios son adultos que se inscriben en un programa educativo después de haber dejado la escuela por un lapso sustancial de tiempo; frecuentemente ya han formado una familia y han trabajado, y su motivación principal es el deseo de incrementar su inversión en capital humano (Sweet y Moen, 2007; Hostetler, 2008).

Al respecto Brinton (1993: 79, en Astone et al., 2000) define el sistema de inversión en capital humano anterior como difuso, ya que permite la inversión educativa a lo largo de la vida. Lo distingue del sistema condensado, en el que las oportunidades de invertir en la educación formal se limitan a edades particulares o a puntos específicos del curso de vida, generalmente tempranas, con pocas opciones para hacerlo después de esas etapas. Para el caso mexicano el sistema condensado es el que predomina, lo que explica en gran medida el que aquí los reingresos escolares hayan merecido menos atención.

Parte de los trabajos realizados en Estados Unidos se han enfocado en la población femenina, ya sea blanca o afroamericana, debido a que en sus primeros años como adultas las mujeres tienden a anteponer a sus estudios la carrera de sus esposos y el cuidado de sus hijos y de su hogar, y ya cuando se encuentran en etapas más tardías del ciclo familiar deciden regresar a la escuela, por lo que sus trayectorias escolares se acercan menos al modelo normativo del curso de vida (Bradburn, Moen y Dempster-McClain, 1995).

Entre los temas tratados en dichos estudios destaca el examen de los agentes que motivan a las mujeres a matricularse nuevamente después de haberse casado y tenido hijos (Bradburn, Moen y DempsterMcClain, 1995), así como los que precisan los elementos que las llevan a dejar sus trabajos de tiempo completo para atender la escuela (Felmlee, 1988). 
Otra línea de investigación se enfoca en estudiar las motivaciones y obstáculos, así como los sistemas de apoyo emocional, financiero, actitudinal y de conducta con que cuentan aquellas mujeres que regresan a estudiar, ya sea que se los brinden su red social, comunitaria y escolar (Thomas, 2001), sus madres (Suitor, 1987) o sus esposos (Berkove, 1979; Suitor, 1988).

En conjunto, los escritos reportan resultados positivos y negativos cuando las mujeres realizan esta transición. Entre los positivos se encuentran los incrementos en su autoconfianza, en su salario y en su prestigio laboral cuando se reintegran a la fuerza de trabajo. Destacan entre los negativos las limitaciones financieras, el racismo y el sexismo que las mujeres experimentan en su casa, en su trabajo y/o en la escuela, así como las barreras estructurales que impiden que logren ver concretizados los beneficios económicos y de prestigio que esperan se derivarán de la escolaridad (Felmlee, 1988; Thomas, 2001).

Aunado a ello, las mujeres enfrentan conflictos entre los roles maritales, estudiantiles y laborales, así como mayores cargas de trabajo ante la falta de apoyo instrumental de sus esposos, ya que ellas reportan pocos cambios en la división tradicional dentro de la familia una vez que regresan a la escuela (Berkove, 1979; Suitor, 1988; Thomas, 2001; Sweet y Moen, 2007).

$\mathrm{Al}$ respecto se ha establecido que la falta de apoyo, sobre todo por parte de los esposos de las que retoman la escuela, incrementa los niveles de estrés que les generan las responsabilidades escolares extra a las que se enfrentan (Berkove, 1979; Suitor, 1988). En contraste se ha observado que tanto las mujeres como los hombres que cuentan con apoyo familiar y laboral y que se encuentran satisfechos con su regreso a la escuela, ven disminuida la posibilidad de enfrentar estrés (Kirby, Biever, Martínez y Gómez, 2004).

Una gran variedad de estudios se ha orientado a establecer los factores que facilitan el surgimiento de esta transición. En la población afroamericana tanto de hombres como de mujeres se precisa que el regreso escolar está en función del costo que les representa el volver a la escuela, así como de la probabilidad de éxito que perciben y de la utilidad que esperan de ésta (Astone, Schoen, Ensminger y Rothert, 2000).

Entre las mujeres blancas y no blancas se ha determinado que ser soltera, no tener hijos, ser joven y laborar en empleos de baja remuneración económica, o en labores en que han permanecido durante periodos cortos de tiempo, son las variables que afectan positivamente su reingreso escolar (Felmlee, 1988; Hostetler, Sweet y Moen, 2007). 
Una vez casadas y con hijos, las mujeres que previamente tenían niveles de escolaridad más altos, que se ajustan a roles de género no tradicionales, que pertenecen a cohortes más jóvenes, que han vivido algún divorcio o separación marital o que han estado insertas en empleos de tiempo parcial, son quienes mayores probabilidades tienen de regresar a la escuela (Bradburn, Moen y Dempster-McClain, 1995).

A los varones el obtener ingresos por debajo de las ganancias esperadas puede motivarlos a retomar sus estudios, al considerar que los incrementos en su escolaridad les generarán aumentos salariales (Marcus, 1986).

Se han examinado las transiciones de trabajo y escuela en parejas de clase media donde los dos trabajan, y en las cuales alguno de ellos o los dos han regresado al sistema escolar, y se han comparado las diferencias por sexo en su interior. Contrario a lo que se esperaría, en esta población son las mujeres con mayores demandas familiares y laborales quienes cuentan con más probabilidades de regresar a la escuela como una estrategia para ponerse al día y lograr metas profesionales que habían diferido (Hostetler, Sweet y Moen, 2007).

Aunado a esto, se ha contrastado a estas parejas con aquellas en donde la esposa nunca regresó a la escuela a fin de analizar la redefinición de roles familiares, la satisfacción marital y el efecto que tiene en la calidad de vida familiar el que la mujer continúe con sus estudios. Se destaca que gracias a las estrategias familiares y de género que ponen en marcha las mujeres junto a su familia en las primeras etapas de su desarrollo, pueden regresar a las aulas educativas (Sweet y Moen, 2007).

\section{La teoría del capital humano y el enfoque del curso de vida}

La teoría del capital humano reconoce a la educación como una inversión que redundará en las ganancias de toda una vida y considera los atributos individuales y las condiciones del mercado laboral como factores que influyen en la decisión de permanecer en la escuela y/o de regresar a la misma entre aquellos que ya la han dejado.

El enfoque del curso de vida por su parte, enuncia la existencia de posibles eventualidades en la configuración de las elecciones que los individuos realizan basándose en decisiones prioritarias, en su estatus actual y en la configuración espacial e histórica de oportunidades. Esto le permite considerar el efecto de los eventos y circunstancias históricas en las vidas individuales, familiares y comunitarias, las cuales son mu- 
tuamente dependientes en el proceso del cambio social (Elder, 1985; Elder y M. O’Rand, 1995; Elder, Kirkpatrick y Crosnoe, 2003).

Dentro del enfoque del curso de vida Bradurn y colaboradores (1995) identifican tres aspectos principales que se conjugan en la decisión de regresar a la escuela. Primero, las experiencias tempranas influyen en las subsecuentes elecciones de vida; segundo, las transiciones se encuentran frecuentemente supeditadas a otros roles de la trayectoria vital; y tercero, las transiciones del curso de vida están imbricadas dentro del contexto histórico, el cual influye en las oportunidades y en las motivaciones de regresar a la escuela.

\section{Capital humano y movilidad social}

Las inversiones en tiempo, dinero y esfuerzo para obtener un mayor capital humano pueden ser consideradas como un esfuerzo instrumental en la búsqueda de un mayor estatus social, lo cual se ve reflejado en las aspiraciones de movilidad, tanto individuales como familiares. Después de la salud y la nutrición, la educación es la más importante inversión en capital humano que las familias y los individuos hacen para influir a mediano y largo plazos en las ganancias económicas, culturales y de redes sociales, así como en el bienestar en general. Las investigaciones muestran una fuerte relacional lineal entre el número de años completos de escolaridad y las ganancias económicas posteriores, lo que provee de fuertes incentivos para permanecer en la escuela o para regresar a la misma a fin de incrementar el nivel educativo (Card, 1999).

Sin embargo, en la primaria como en la secundaria el sistema educativo mexicano se encuentra graduado por edad, con una fuerte correspondencia entre ésta y el grado escolar. Dicho sistema dificulta que los jóvenes que han interrumpido sus estudios en esos niveles los retomen posteriormente. La estricta correspondencia entre el nivel de educación y la edad progresiva se debilita en el nivel medio superior y más en el profesional, permitiendo entonces que las posibilidades de retomar los estudios sean mayores en estos niveles, ya que los obstáculos asociados a la edad se atenúan. Ante esa situación se formula la siguiente hipótesis:

H1. Las personas que cuentan con alta escolaridad al momento de dejar la escuela tendrán un mayor riesgo de regresar al sistema escolar en comparación con aquellas que al dejarla tenían un bajo nivel educativo. 


\section{Edad}

La edad, como construcción social, contribuye a diferenciar el curso de vida. En la mayoría de las sociedades occidentales dicho curso está parcialmente diferenciado por la edad, con roles sociales y actividades asignados sobre la base de la edad o de un periodo de la vida (Settersten, 2003).

Las expectativas por edad definen los tiempos apropiados para la mayoría de las transiciones dependiendo de la etapa de la vida en que las personas se encuentren. Ello a su vez varía según sea la sociedad. Dentro de cada colectividad hay una edad apropiada para cada transición, y conforme las personas se mueven en la estructura por edad se les hace saber si están realizando a tiempo dicha transición o rol, o por el contrario, si lo han hecho muy temprano o muy tarde (Elder, 1975 y 1985).

Los ámbitos educativos y laborales están especialmente estructurados por la edad y por el tiempo, y éstos calibran formalmente los movimientos o etapas dentro de estas instituciones. Debido a que la escolaridad incluye inversiones tanto en tiempo como en dinero, se considera que entre más temprano se realicen las inversiones en educación, mayores serán los beneficios económicos en las siguientes etapas del curso de vida. A la vez, retornar a la escuela en edades avanzadas puede ser un evento sancionado mediante sistemas informales que desincentivan a las personas a hacerlo. ${ }^{10}$ Por tanto, la hipótesis al respecto es:

H2. Cuanto mayor sea la edad menor será el riesgo de regresar a la escuela.

\section{Actividad laboral previa al regreso escolar}

En los últimos años se ha documentado que la mayor participación de los jóvenes en la fuerza de trabajo ha ocurrido a costa de la disminución de la población escolar que dedica tiempo exclusivo a sus estudios (Rendón y Salas, 1996). En ese sentido, los hombres históricamente han llevado sobre sí la responsabilidad principal de mantener el hogar, por lo que cuando se presentan contingencias financieras es común que los jóvenes deban comenzar a realizar trabajos extradomésticos para contribuir en los gastos de la casa paterna.

${ }^{10}$ Por ejemplo, hacerlos sentir que por su edad se encuentran desfasados respecto a sus compañeros. 
Ello viene a acarrearles grandes obstáculos para concluir sus estudios, ya que en la mayoría de los empleos se trabaja de tiempo completo, y no les queda oportunidad ni energía para realizar otra actividad, lo que a su vez afecta negativamente sus oportunidades de reingresar al sistema educativo para finalizar posibles estudios truncados o para mejorar su nivel escolar. De esta manera es viable considerar que el trabajo que se realiza de tiempo completo tiende a ser, en la mayoría de los casos, incompatible con la actividad estudiantil.

Aunado a ello, se encuentran los costos de oportunidad asociados con dejar de recibir ingresos económicos y/o en especie en el corto plazo por concepto del trabajo que se realiza, una vez que se regresa a la escuela. Asimismo, en un mercado laboral con opciones limitadas existe un costo de oportunidades de dejar el empleo y salir del mercado para estudiar si no se tiene la seguridad de que una vez concluidos los estudios la persona se podrá reintegrar a su empleo. Por tal, la hipótesis que se desprende es:

H3a. Las personas que se encuentren realizando un trabajo, sea éste remunerado o no, tendrán un menor riesgo de regresar a la escuela en comparación con aquellas que no ejecutan trabajo extradoméstico, debido a los costos de oportunidad asociados con dejar de percibir ingresos económicos en el corto plazo para dedicarle tiempo y esfuerzo a la escuela.

Dada la vigencia en ciertos sectores de la sociedad de la división sexual del trabajo, se espera que el efecto del estatus laboral en el riesgo de regresar a la escuela sea diferente para hombres y mujeres. En el caso de los varones el no realizar una actividad laboral es una situación no normativa, ya que la expectativa es que una vez que llegan a cierta edad se encuentren trabajando, por lo que el estar desempleados pudiera ser una situación que ellos aprovechen para estudiar y continuar preparándose. En contraste, para las mujeres el papel doméstico y el no estar insertas en el mercado laboral son situaciones más comunes y menos sancionadas socialmente, y por tanto no necesitan justificar su ausencia laboral ingresando a un recinto educativo. La hipótesis al respecto es:

H3b. El efecto de no realizar trabajo remunerado en el riesgo de regresar a la escuela será mayor para las mujeres que para los hombres. 


\section{Efectos de la migración}

Los estudios de migración han reportado que la población migrante es selectiva y muestra características positivas asociadas con mayores aspiraciones, no sólo económicas, laborales y de movilidad social, sino también educativas (Lindstrom y López Ramírez, 2010). En ese sentido, se sabe que los migrantes no pueden ser considerados como una muestra representativa de los pobladores que se quedan en su lugar de origen. Sjaastad (1962) considera que la migración es una inversión en capital humano que influye en el flujo de ingresos a lo largo del curso de vida. Por tal razón se ha observado que la tendencia a migrar es más alta entre los adultos jóvenes, quienes tienen más tiempo para recibir y disfrutar de las recompensas económicas producto de la migración. Las personas, principalmente los jóvenes, pueden migrar no sólo buscando mejores condiciones de empleos, sino también para tratar de acercarse a los lugares en donde se ofrecen niveles superiores de educación. Dada la positiva relación entre la migración y la expectativa de mejorar los ingresos se hipotetiza que:

H4. La experiencia migratoria previa está asociada con un mayor riesgo de regresar a la escuela al intentar mejorar sus oportunidades de vida.

\section{Zona de residencia}

De acuerdo con el principio del lugar enunciado dentro del curso de vida, el espacio no sólo contiene una localización geográfica, sino también es portador de formas materiales y culturales características, y por tanto de significados y valores, por lo que una misma transición o evento puede diferir en sustancia y significado en distintos lugares. A pesar de la mejora en el nivel educativo, en el país existen grandes diferencias por localidad de residencia. La población rural es la que mayormente se ve afectada por la salida anticipada de la escuela; es asimismo la que registra menores niveles de asistencia en el nivel adecuado, así como altos índices de reprobación, atraso y deserción escolar (Parker y Pederzini, 2000; Camarena, 2000; Tuirán y Zúñiga, 2000; Mier y Terán y Rabell, 2001; Giorguli, 2002; Echarri y Pérez Amador, 2007).

Los diferenciales educativos por localidad de residencia se explican por el hecho de que en las áreas urbanas históricamente se han presentado los mayores incrementos en la creación de escuelas adiciona- 
les, públicas y privadas, que ofrecen distintos programas de estudio, enfocados tanto a la población infantil como a la juvenil y a la adulta. Es común que dichas escuelas estén mejor equipadas y se encuentren mejor localizadas y que por tanto sea más fácil acceder a ellas (Parker y Pederzini, 2000). Asimismo, en estas áreas hay un mayor desarrollo económico y social y una diversificación del mercado laboral, especialmente respecto a la demanda de trabajadores altamente calificados o con estudios avanzados. La mayor disponibilidad de puestos de trabajo en que se requieren altos niveles de educación en espacios urbanos representa un fuerte incentivo para regresar a la escuela.

En cambio en la zona rural las condiciones económicas y los escasos requerimientos de formación escolar que demandan los empleos del área pueden influir en las expectativas educativas de los padres, y esto ocasiona que los hijos asistan menos a la escuela (Mier y Terán y Rabell, 2001). En ese sentido se considera que:

H5. La población urbana tiene más oportunidades educativas y mayores posibilidades de incrementar sus recompensas económicas y laborales al aumentar su nivel de escolaridad, por lo que su riesgo de regresar a la escuela es mayor que el de la población rural.

\section{Ocupación de los padres}

El temprano contexto de socialización es parte fundamental en el establecimiento de las aspiraciones y de los planes vitales de las personas en sus siguientes fases de la vida. Los jóvenes cuyos padres tuvieron una posición social alta tienen mayores probabilidades de presentar a su vez amplias ambiciones para ellos mismos, ya que los padres les transmiten aspiraciones similares. Esto en concordancia con el principio de las vidas interconectadas, mismo que enuncia que la interdependencia de las personas afecta el proceso de autodesarrollo personal (Elder y M. O'Rand, 1995). En este sentido la hipótesis que se busca probar es:

H6. Un mayor estatus ocupacional del padre o la madre cuando el entrevistado/a era adolescente se asocia con un mayor riesgo de regresar a la escuela. 


\section{El conflicto del rol}

La idea de un curso de vida ordenado en el que existen normas sociales que indican la secuencia apropiada de los roles y el calendario de cada transición es un componente fundamental de la teoría del curso de vida. Se le denomina "conflicto de rol" a ciertas actividades que se considera no pueden realizarse de manera simultánea, ya que demandan de la persona tiempo y esfuerzo en ámbitos muy diferentes. Asimismo se estima que algunos de estos roles deben ser realizados en una primera etapa para preparar al individuo en sus subsiguientes actividades. Tradicionalmente el papel de estudiante se considera mutuamente excluyente de los roles realizados en el ámbito familiar, como ser esposo o esposa y padre o madre (Lindstrom y Brambila, 2001).

Ello debido a que el mantenimiento del hogar y los deberes en torno al cuidado de los menores toman prioridad sobre otras obligaciones, limitando a su vez el tiempo que se dedica a otras actividades. Esto afecta la permanencia y en su caso el regreso a la escuela de quienes están casados, pero sobre todo de aquellos que son padres. También puede esperarse lo contrario, es decir, aquellos que desean continuar en la escuela verán reducido el riesgo de casarse o de tener hijos mientras asisten a la misma. Por tanto se espera que:

H7a. Estar soltero, separado o divorciado se asocia con un mayor riesgo de regresar a la escuela.

H7b. Tener hijos en el hogar se asocia con un menor riesgo de regresar a la escuela.

Los roles familiares tradicionales en México asignan a las mujeres casadas la responsabilidad principal de ejecutar las tareas del hogar y cuidar y educar a los hijos, en tanto que los hombres tienden a asumir la responsabilidad económica al ser considerados como los principales y en ocasiones los únicos proveedores económicos, en concordancia con el modelo de especialización y complementariedad entre los cónyuges de la economía del hogar propuesto por Gary Becker (1981).

Aun cuando la segregación de las mujeres al ámbito doméstico ha perdido fuerza y ha crecido la tasa laboral femenina, todavía es bajo el porcentaje de mujeres casadas que realiza trabajo extradoméstico remunerado en México en comparación con la población económicamente activa (PEA) de los países altamente desarrollados. Ello debido 
a la persistencia de fuertes normas culturales en ciertos grupos que dan un alto valor a las contribuciones de las mujeres en la producción doméstica y en el cuidado de los hijos, a la vez que consideran secundarias y complementarias las aportaciones económicas que éstas pudieran hacer a hogares con jefatura masculina. Por tal se hipotetiza que:

$H 7 c$. El efecto del estado civil sobre el riesgo de regresar a la escuela es mayor para las mujeres que para los hombres.

$H 7 d$. Las mujeres con hijos tienen menos probabilidades de regresar a la escuela que los hombres con hijos.

\section{Cambio histórico}

Las ganancias económicas asociadas a la inversión en educación cambian en el tiempo en respuesta a las transformaciones del mercado laboral provocadas por el desarrollo económico. Durante el siglo XX México transitó de una economía principalmente agraria a una sociedad industrializada, con una relativamente amplia producción manufacturera, la cual más recientemente se ha basado en el crecimiento del sector servicios.

Con el aumento del empleo manufacturero y de servicios se ha presentado una creciente demanda de trabajadores con mayor escolaridad, capacitación y habilidades técnicas. Al mismo tiempo el sistema educativo se ha ampliado, permitiendo que más personas, sobre todo de las cohortes jóvenes, accedan a mayores niveles de escolaridad. El incremento intergeneracional de las oportunidades educativas, junto con el aumento de la demanda de trabajadores con niveles más altos de educación, proporciona fuertes incentivos y mayores oportunidades para que las personas jóvenes regresen a la escuela. Por ello esperamos que:

$H 8 a$. El riesgo de regresar a la escuela es mayor entre las cohortes más jóvenes en comparación con las más antiguas.

Aunado al incremento de las oportunidades educativas, se ha presentado una gradual reducción en la brecha educativa por género entre las cohortes más recientes de mexicanos. Dicha brecha casi ha desaparecido en los niveles de primaria y secundaria, y si bien en los 
niveles altos de la educación los hombres tienden a tener una mayor escolaridad que las mujeres, la diferencia ha llegado a ser relativamente pequeña. Por ello se hipotetiza que:

$H 8 b$. El riesgo de regresar a la escuela será mayor entre las mujeres de la cohorte joven en comparación con los hombres de esta cohorte, lo cual es consistente con la progresiva reducción de la brecha en el logro educativo por género y con el gradual incremento de la participación laboral femenina.

\section{Datos y métodos}

Para el estudio del retorno escolar se empleó la Eder 1998 como fuente de información. Su población objeto la constituyó una submuestra de 3200 personas de la Encuesta Nacional de la Dinámica Demográfica (Enadid) de 1997. La encuesta se enfoca en la historia individual año por año de tres cohortes de nacimiento de mexicanos: 1936-1938, $1951-1953$ y 1966-1968, mismos que tenían entre 30 y 62 años al ser entrevistados. La muestra final está compuesta por 118800 observaciones correspondientes a cada uno de los años de vida de 2496 individuos que respondieron de manera completa el cuestionario. La tasa de no respuesta fue del 22\% (Coubès, Zavala de Cosío y Zenteno, 2005).

Además de la cohorte, la muestra es representativa del país para ambos sexos y para dos tamaños de localidad (menos de 15000 habitantes y 15000 y más). Estos últimos son mencionados en la fuente de datos como "rural" y "urbano" (Coubès, Zavala de Cosío y Zenteno, 2005). ${ }^{11}$

En este artículo nos enfocamos en aquellas personas que habiendo comenzado su escolaridad la dejaron en algún momento, sea por conclusión o por abandono, sin hacer distinción de ello, ya que la fuente no lo permite. Definimos la variable dependiente regreso escolar a partir del hecho de haberse reincorporado al sistema educativo durante al menos un año. Se usaron las historias personales contenidas en la Eder para generar un archivo de años-persona en donde cada renglón corresponde a un año de vida de un individuo fuera de la escuela y expuesto al riesgo de regresar a la misma.

${ }^{11}$ Para este ejercicio se tomó la base de datos rural y urbana. A su vez, en el momento de realizar los modelos de historia de eventos se precisó si la población había vivido en zonas rurales o urbanas un año antes de haber regresado a la escuela o en su caso, de haber sido encuestadas. 
Un intervalo fuera de la escuela comienza con el primer año que sigue después de haberla dejado y termina cuando el sujeto se reintegra al sistema escolar o al momento de la encuesta para aquellos que no regresaron; en tal situación los casos están censurados al lado derecho. Los que no han regresado a la escuela contribuyen con un intervalo de salida y los que se han reinscrito al sistema escolar y lo han dejado por segunda vez hacen una contribución de dos intervalos. Del total de personas, el $8.5 \%$ regresó a la escuela una vez y el 1.8\% regresó dos o más veces. La duración mediana entre la salida y el regreso de la escuela fue de cuatro años (el número de observaciones fue de 2 111). Una ventaja de la Eder es que recolecta no sólo historias educativas, sino también laborales, migratorias, matrimoniales y de nacimientos, factores que afectan el riesgo de retornar a la escuela. Usando dichas historias de vida se puede analizar el efecto de los distintos estados sociodemográficos en el riesgo de regresar a la escuela de una forma dinámica a través de modelos logísticos de tiempo discreto, ya que éstos permiten captar los cambios en tales estados y analizar los intervalos fuera de la escuela, así como determinar los factores asociados con dicha transición (véase Allison, 1984).

La variable dependiente es el regreso a la escuela, misma que fue codificada como 1 si la persona regresó a la escuela y 0 si ello no ocurrió, y las independientes son: antecedentes escolares, condición de actividad, experiencia migratoria, zona de residencia, ocupación de los padres, estado civil, presencia de hijos, y cohorte de nacimiento. Todas, excepto la última, se rezagaron un año antes tanto en el análisis descriptivo como en los modelos de tiempo discreto a fin de evitar endogeneidad entre la variable dependiente y las demás variables.

Los modelos de historia de eventos se estimaron usando una regresión logística, misma que permite tener el logaritmo de la razón de momios de la variable dependiente. Si la razón de momios es menor que uno, el efecto de la variable independiente disminuirá el riesgo de regresar a la escuela, en tanto que si esta razón es mayor que uno, la variable independiente aumentará su riesgo en esa magnitud. Se incluyó un conjunto de variables dummy en las variables categóricas.

\section{Estadísticas descriptivas}

La gráfica 1 presenta la distribución por edad y sexo al momento de retornar a la escuela. Por sexo la participación se presentó levemente 


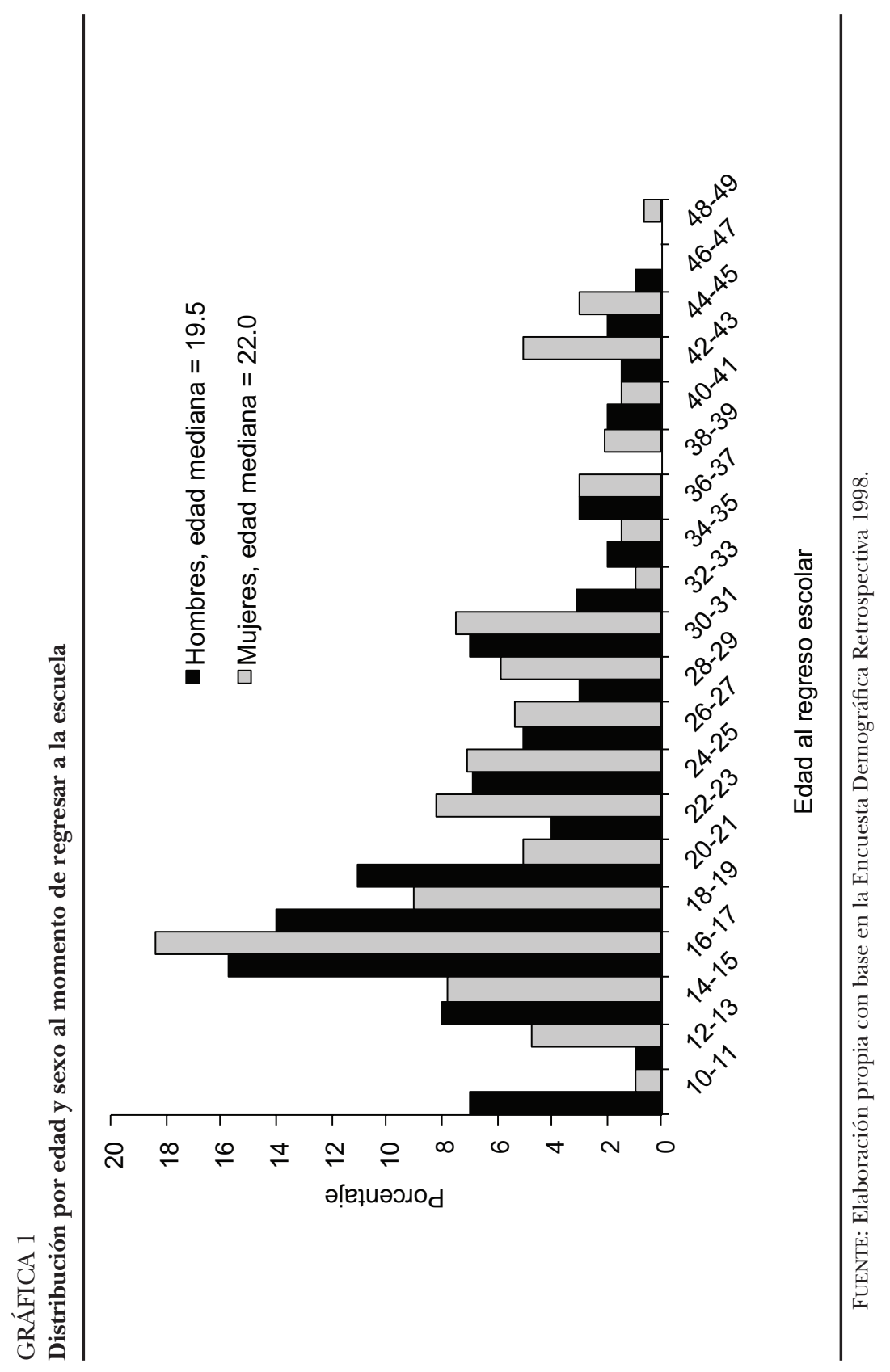


cargada hacia los hombres con $52 \%$, mientras que las mujeres contribuyeron con $48 \%$. Por edad se aprecia una mayor concentración entre los 16 y los 17 años en las mujeres, en tanto que en los varones la mayor congregación se presentó entre los 16 y los 21 años; es decir, ellos tuvieron la posibilidad de integrarse nuevamente al sistema escolar por un espacio más amplio de tiempo en comparación con las mujeres. Luego de estas edades los porcentajes decrecen en ambos sexos, sin presentarse una tendencia definida. La principal diferencia encontrada en este rubro es la edad mediana de hombres y mujeres, que es mayor para ellas. Esto pudiera deberse a que las mujeres pudieran estar retornando a la escuela luego de haber tenido al menos a su primer hijo y tras haber pasado las primeras etapas de crianza, y por tanto su edad mediana se sitúa en los 22 años.

En adelante se presentan las características de los años de vidapersona, que en este apartado es la unidad de análisis, divididos por sexo y atendiendo a que hubieran regresado o no a la escuela. Para los que retomaron sus estudios se muestran los promedios basados en los años de la vida en que se presentó el regreso a la escuela y se comparan con los promedios de quienes no regresaron. Este último dato incluye tanto a los que nunca retornaron como a aquellos que sí lo hicieron, pero no en el año en que se está haciendo la comparación.

Puesto que por definición la población que se reincorporó ya contaba con un historial educativo previo, se buscó precisar sus características escolares un año antes de volver (cuadro 1). De esta manera se observó una mayor presencia de personas, sobre todo varones, con mejores niveles educativos (de secundaria, ${ }^{12}$ bachillerato ${ }^{13}$ y estudios universitarios $)^{14}$ entre aquellos que regresaron a la escuela, en comparación con la población que no lo hizo, de la cual la gran mayoría se ubicó en el nivel de primaria. Ello estaría indicando que esta transición, más que ser realizada por quienes tenían más bajos niveles de estudio y deseaban retornar a la escuela para concluir su escolaridad básica, fue hecha por quienes querían continuar incrementando su nivel formativo.

Igualmente se aprecia que en cada nivel las mujeres retomaron sus estudios en porcentajes más o menos similares a los de los varones; la excepción se presentó en aquellas que contaban con algún grado

\footnotetext{
${ }^{12}$ Esta categoría está compuesta por aquellos que tenían secundaria o eran técnicos con primaria.

${ }^{13}$ La categoría contiene a quienes habían cursado algún bachillerato o eran técnicos con secundaria.

${ }^{14}$ En esta categoría se agrupó a los que habían estudiado la normal básica, eran técnicos con bachillerato o contaban con una licenciatura o posgrado.
} 
universitario, mismas que regresaron a la escuela en porcentajes más bajos que su contraparte masculina. Sin embargo en general se observaron menores diferencias por género al momento de regresar a la escuela en comparación con otras transiciones escolares, tales como la salida de la escuela, en que el calendario es marcadamente diferenciado para los hombres y para las mujeres.

Por condición laboral se precisó que seis de cada diez hombres que se reinscribieron en la escuela contaban con un trabajo remunerado, mientras que entre los que no regresaron la proporción se situó en cerca de ocho de cada diez. Asimismo, el porcentaje de hombres que no estaban trabajando un año antes de retomar los estudios fue más alto entre quienes sí regresaron a la escuela que entre aquellos que no lo hicieron. Entre las mujeres fue más común que aquellas que percibían un salario por su trabajo se vieran motivadas a regresar a la escuela en comparación con las que no lo hicieron, quizá como una estrategia para mejorar sus ingresos económicos. Aunque en definitiva, y a diferencia de los hombres, la mayoría de las mujeres que retornaron no se encontraba desempeñando una actividad extradoméstica un año antes.

Se esperaría que aquellas personas que migran, ya sea hacia otros estados o al interior de su mismo estado, pudieran ser individuos que buscan mejorar sus niveles de vida, por lo que sería factible que realizaran una mudanza para acercarse a los centros educativos más avanzados. Sin embargo, en el caso de las mujeres son pocas las diferencias que se observan entre las que se reincorporaron a la escuela y aquellas que no lo hicieron por condición migratoria. Entre los varones, en cambio, se observa un porcentaje mayor de personas con experiencia previa de migración entre quienes sí regresaron a la escuela, en comparación con los que no lo hicieron.

Por zona de residencia se observó una sobrerrepresentación de la población urbana, tanto varonil como femenil, entre quienes sí retomaron sus estudios, señal indiscutible de la existencia de una mayor oferta educativa y de una importante demanda de personal altamente calificado en los empleos ubicados en el área urbana. Entre aquellos que no volvieron al sistema escolar no se observó una diferencia tan marcada por localidad de residencia.

Como una variable proxy del nivel de bienestar de las familias de origen de estas personas se empleó la ocupación del padre a los 15 años del entrevistado ${ }^{15}$ a fin de observar su influencia en el retorno

${ }^{15}$ En los casos en que se reportó la ausencia del padre se recurrió a la ocupación de la madre para crear esta variable. 


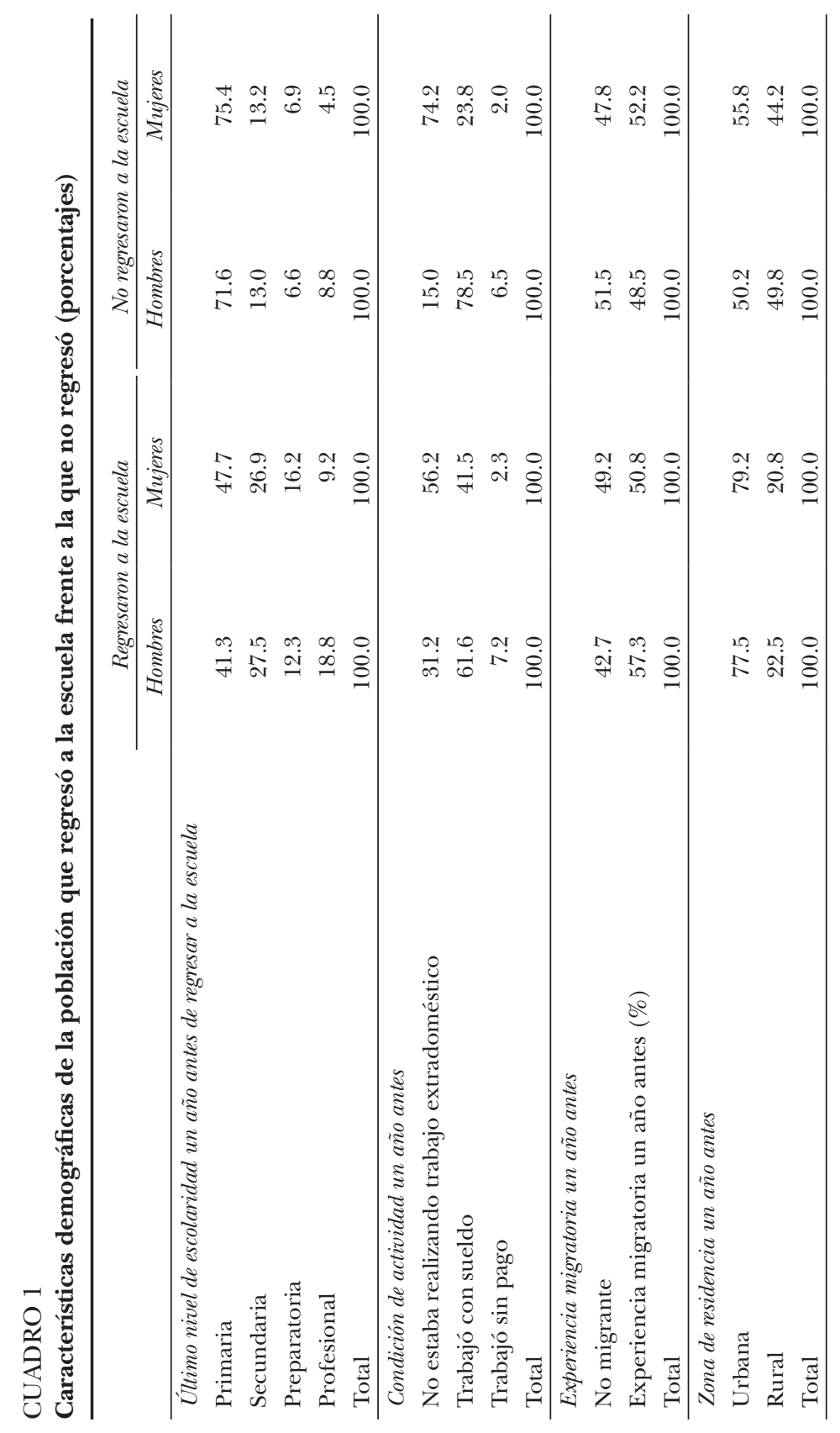




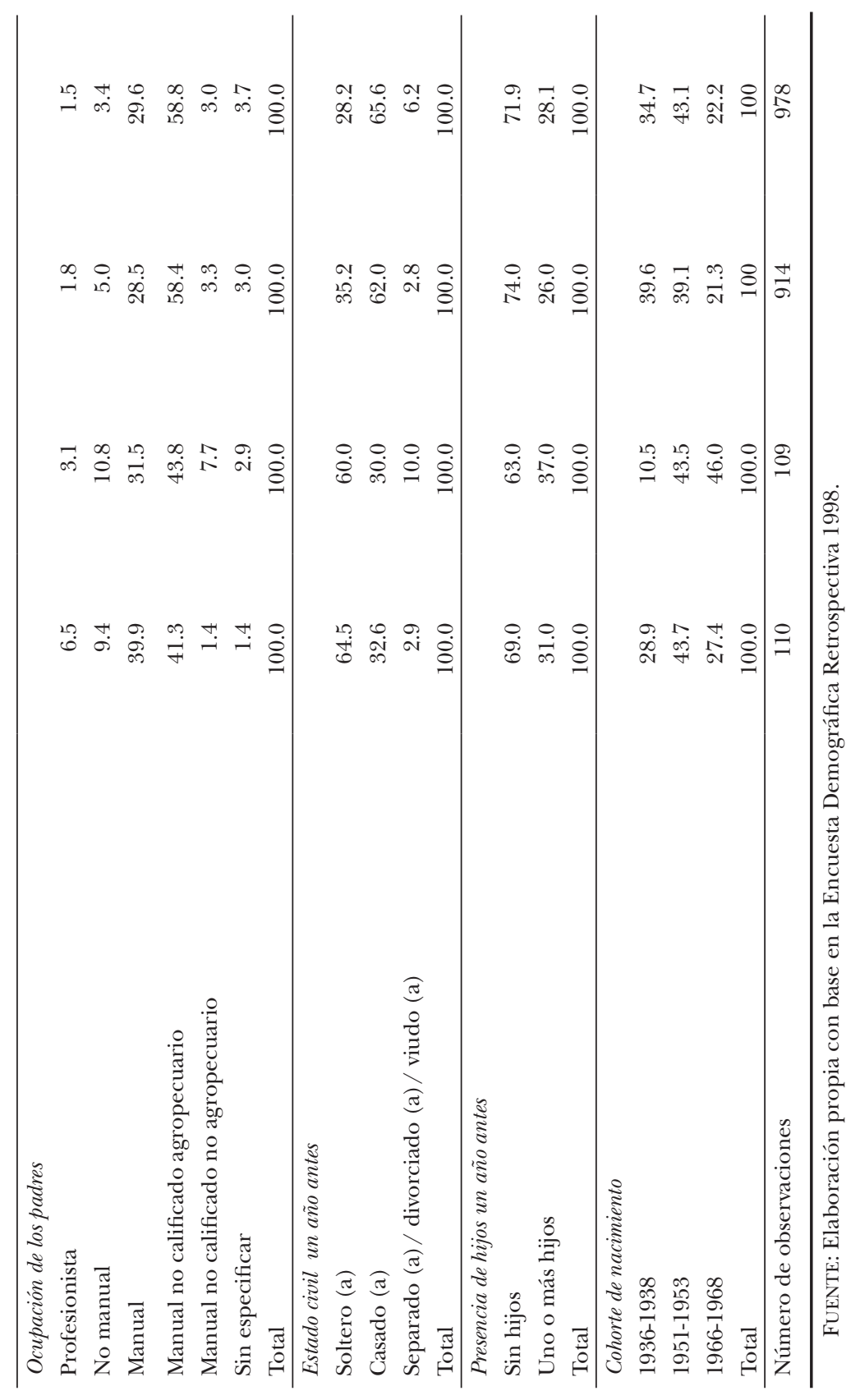


escolar de los entrevistados. Los resultados indican que los individuos, principalmente varones, cuyos padres se desempeñaron como profesionistas o en actividades no manuales, estuvieron mayormente representados entre quienes regresaron a la escuela, mientras que entre quienes no regresaron fueron muy bajos los porcentajes en estas categorías, especialmente en las mujeres.

Sin embargo, el mayor porcentaje de personas reincorporadas se presentó entre aquellos que habían crecido en hogares cuyo proveedor económico realizaba actividades manuales y sobre todo actividades manuales no calificadas agropecuarias, sin que se hayan observado grandes diferencias por género. Al respecto, es muy posible que ante sus difíciles condiciones de vida, éstos hayan visto más limitadas sus opciones de continuar en la escuela cuando se encontraban en edades escolares, y por lo tanto decidieran retomar sus estudios ya en la adultez.

Entre la población femenina y masculina promedio que no regresó a la escuela fue todavía mayor el porcentaje que contó con un padre dedicado a actividades manuales y manuales no calificadas agropecuarias. La marcada representación de hijos de trabajadores del campo, tanto entre quienes se reinscribieron en el sistema escolar como entre quienes no lo hicieron, tiene su explicación en el desarrollo económico del país, que a principios del siglo pasado era eminentemente agrícola, y entre 1940 y 1960 comenzó su acelerada urbanización. Sin embargo, todavía para 1980 coexistían las grandes metrópolis con un México rural y tradicional.

En el ámbito de la vida familiar se exploró primeramente el estado civil de los encuestados; se precisó que el mayor porcentaje de hombres $(64.5 \%)$ y de mujeres $(60 \%)$ que volvieron a estudiar eran solteros, mientras que cerca de un tercio de quienes retornaron eran casados. Destaca también que una de cada diez mujeres que había concluido su unión conyugal, ya sea por separación, divorcio o fallecimiento del cónyuge, se reincorporó al sistema educativo. El mayor porcentaje de personas que no regresaron a la escuela correspondió a los casados.

A sabiendas del conflicto de roles que guardan las transiciones del ámbito familiar (especialmente el tener hijos), y las obligaciones que implica el ser estudiante, se exploró la presencia o ausencia de hijos. Al respecto se precisó que casi dos tercios de quienes regresaron a la escuela no tenían hijos, y que este porcentaje era levemente mayor entre los varones, mismos que respondieron al perfil típico del estudiante promedio, por tanto el regresar a la escuela no les generó conflictos de rol con su vida familiar. 
$\mathrm{Al}$ analizar por cohortes se observa una mayor presencia de los hombres de la cohorte intermedia entre quienes volvieron a estudiar. En las mujeres la mayor representación fue de aquellas que pertenecían a las dos cohortes más jóvenes, y sólo una de cada diez formaba parte de la más antigua. En contraste, aquellos que no regresaron a la escuela se concentraron mayormente en las dos cohortes más antiguas.

\section{Análisis multivariado}

Con la finalidad de probar la asociación estadística de las variables analizadas con el regreso a la escuela se realizó un modelo logístico de tiempo discreto. En él se observa que la probabilidad de regresar a la escuela no fue diferencial entre hombres y mujeres, lo cual ya se había ido delineando en el análisis descriptivo anterior, por lo que no se consideró necesario efectuar un modelo para cada grupo (cuadro 2).

Los antecedentes escolares de las personas jugaron un papel importante en esta transición, ya que tener una escolaridad previa de secundaria o más aumentó la probabilidad de que las personas volvieran a estudiar. El riesgo mayor se concentró entre quienes ya habían cursado algún grado de secundaria, quienes posiblemente retomaron sus estudios del nivel medio superior o trataron de aprender un oficio. Los dos niveles siguientes también presentaron una fuerte influencia en el momento de reinscribirse en la escuela, lo que parece indicar la presencia de una selectividad entre las personas que volvieron a estudiar, dada por una media y alta escolaridad previa.

La edad mostró una asociación negativa con el regreso a clases. De esta manera, las personas vieron disminuido su riesgo de retomar los estudios con cada año que ganaron de vida. Sin embargo, la edad al cuadrado indica que en cierto momento este riesgo se estacionó en el tiempo. Ello concuerda con la gráfica 1, misma que demuestra una presencia marcadamente juvenil en el retorno escolar de estas tres cohortes y una progresiva disminución en las edades adultas.

La experiencia migratoria previa también resultó ser un factor asociado positivamente al retorno escolar. Asimismo, haber residido en zonas urbanas el año anterior fue un factor que contribuyó positivamente en el retorno al sistema educativo, en comparación con quienes vivían en áreas rurales, lo cual era esperable dadas las mayores oportunidades educativas y laborales que pueden encontrarse en las ciudades. 


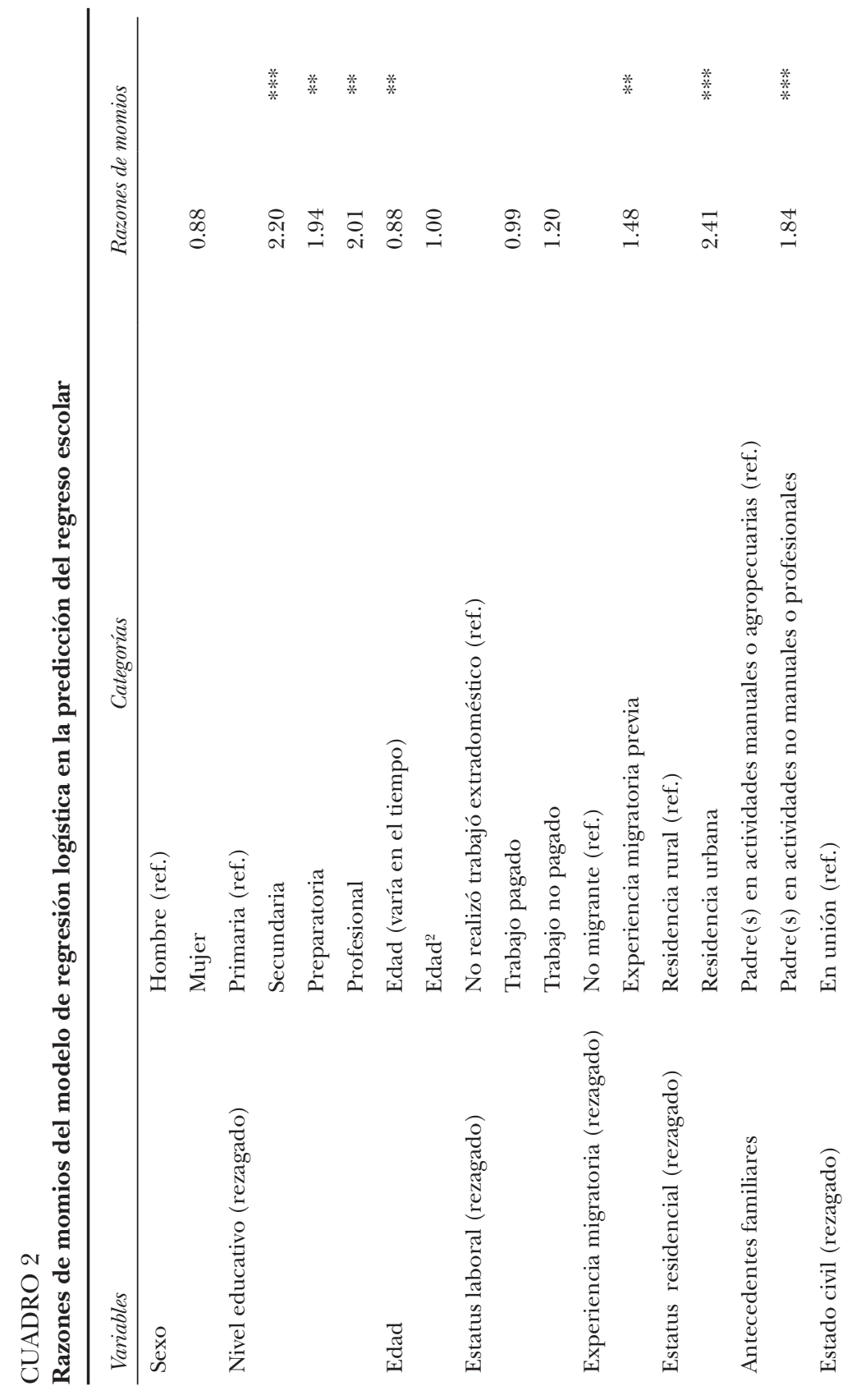




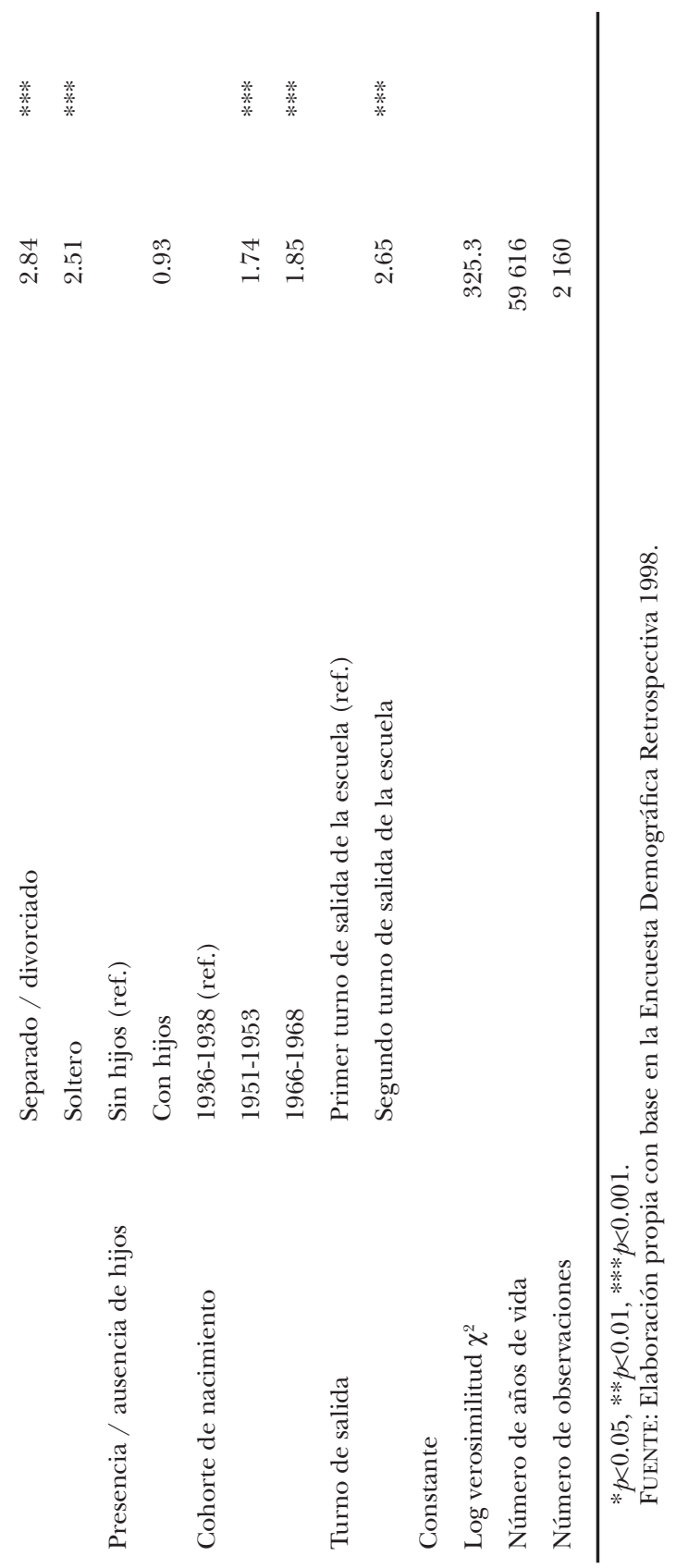


Aquellos que tuvieron padres que desempeñaban actividades no manuales o eran profesionistas cuando el entrevistado tenía 15 años, vieron aumentado su riesgo de retomar sus estudios en comparación con quienes tuvieron padres que realizaban actividades manuales, agropecuarias o no agropecuarias. Ello muestra la influencia que la ocupación paterna tiene sobre los hijos no sólo en los años de socialización, sino a lo largo de la vida, pues los motiva a continuar estudiando como una estrategia para lograr una movilidad social similar o superior a la de sus progenitores.

En cuanto al estatus familiar del alumno, se precisó que estar soltero, pero sobre todo separado o divorciado un año antes, fueron factores que permitieron el regreso a la escuela, tomando como referencia a quienes vivían en unión conyugal; en cambio tener hijos no hizo diferencia alguna en esta transición.

El cambio social, sintetizado a través de la cohorte de nacimiento, fue un factor importante al medir el logro escolar, ya que los miembros de la cohorte intermedia, y sobre todo de la joven, tuvieron un mayor riesgo de regresar a la escuela en comparación con los de la antigua (los nacidos entre 1936 y 1938).

De igual manera, quienes habían dejado por segunda vez la escuela tuvieron mayores probabilidades de regresar a la misma, ya que seguramente se trataba de población selectiva que periódicamente buscaba actualizar sus conocimientos o que en las ocasiones anteriores no había podido concluir sus estudios debido a circunstancias adversas, y que en ambos casos mostraba mayor perseverancia para retomarlos.

\section{Interacciones}

Si bien el género no resultó ser un factor que influyera en las probabilidades de reinscribirse dentro del sistema escolar, ya que tanto los hombres como las mujeres tuvieron las mismas posibilidades de hacerlo, se presumía que algunas variables tales como la cohorte de nacimiento, el estatus laboral, el estado civil y la presencia de hijos podían tener efectos diferenciales en el retorno escolar de las mujeres. Por ello es que se enunciaron ciertas hipótesis, y para comprobarlas se elaboró un segundo modelo de tiempo discreto que contuviera dichas interacciones; de éstas, la única interacción significativa resultó ser la de la cohorte con el sexo. 


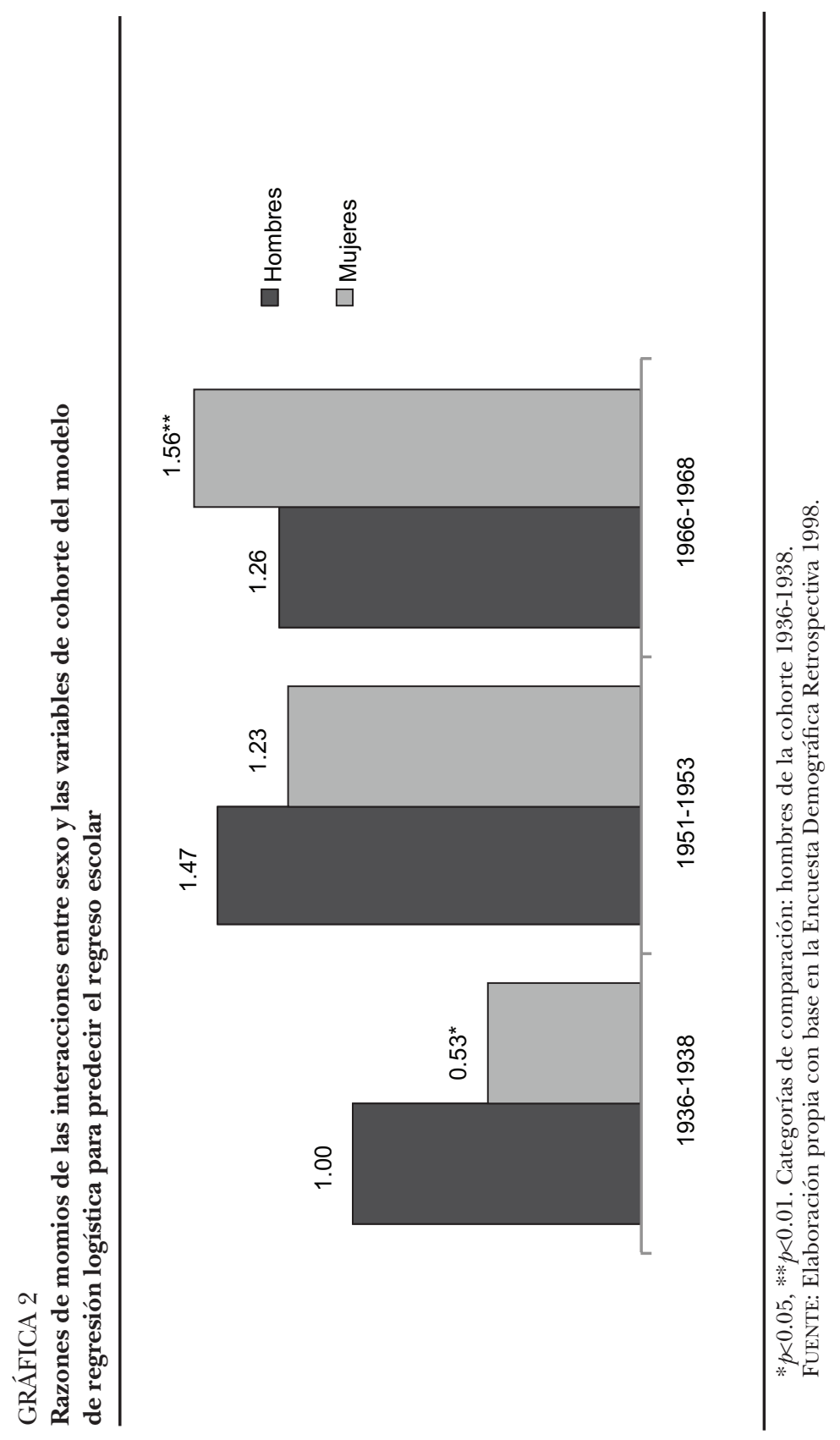


Por cohorte se esperaba ver un mayor riesgo de regresar a la escuela entre las mujeres más jóvenes en comparación con los hombres, ello gracias a la progresiva reducción de la brecha en el logro educativo por género y al gradual incremento de la participación laboral femenina. En la gráfica 2 se observa la tendencia de las mujeres a incrementar su participación escolar conforme las cohortes avanzan, apreciándose que las mujeres de la cohorte antigua tuvieron un menor riesgo de regresar a la escuela, mientras que en la cohorte joven este riesgo fue mayor, esto en comparación con los varones de la cohorte antigua.

En resumen, de las 13 hipótesis planteadas, ocho recibieron apoyo de los resultados. Las que no se confirmaron se refieren al estatus laboral (H3 a) y a la presencia de hijos para ambos (H7 b), así como a la experiencia laboral para las mujeres (H3 b), el estado civil (H7 c) y la presencia de hijos en la vida de ellas $(\mathrm{H} 7 \mathrm{~d})$.

\section{Discusión}

El regreso a la escuela constituye una parte importante en las trayectorias escolares de casi una de cada diez personas, sin embargo han sido pocas las investigaciones realizadas dentro de los estudios de población en México que se han enfocado en el análisis de dicho tema. En ese sentido hemos tratado aquí de conocer las características generales de estas personas, así como los factores asociados a su retorno escolar con miras a establecer su perfil educativo; para ello se propusieron una serie de hipótesis.

En principio se esperaba que fueran las mujeres quienes en mayor medida regresaran a la escuela, dado que la población femenina de las cohortes estudiadas, sobre todo de la más antigua, tuvieron mayores riesgos de dejar los estudios (Mier y Terán y Rabell, 2005; Coubès y Zenteno, 2005; Castro y Gandini, 2006; Pérez Baleón, 2012). Sin embargo, tanto los hombres como las mujeres retomaron sus estudios en porcentajes similares.

Se preveía también que fueran las personas con antecedentes escolares avanzados quienes principalmente volvieran a estudiar. Los resultados muestran que efectivamente, quienes habían cursado secundaria, preparatoria o estudios universitarios tuvieron mayores riesgos de retomar sus estudios en comparación con aquellos que sólo tenían la primaria. Ello pudiera estar denotando el efecto que ciertos 
niveles de educación tienen en los individuos para motivarlos a seguirse preparando, pues hacen una doble diferencia educativa entre personas con baja y alta escolaridad, no sólo al momento de egresar por primera vez de la escuela, sino también al regresar a la misma.

Dado que la educación en México se enmarca dentro de un sistema de inversión en capital humano condensado, graduado por la edad, principalmente en los niveles básicos de la educación (Brinton, 1993), se esperaba que entre más edad tuvieran las personas, menor fuera su riesgo de volver a la escuela. La curva de distribución por edad mostró que aquellos que regresaron eran en su mayoría jóvenes de entre 14 y 31 años. El modelo de tiempo; discreto, por su parte, indicó que a mayor edad, el riesgo de volver a estudiar era menor, aunque éste se estabilizaba en el tiempo; de ahí que todavía se viera la presencia de alumnos retornantes en edades adultas, aunque en mucho menor proporción.

Es posible que la concentración escolar juvenil en el retorno escolar en estas cohortes estuviera respondiendo a un sistema informal de sanciones y recompensas que motivara a los jóvenes a retomar sus estudios a fin de obtener beneficios económicos, laborales y de prestigio a mediano y largo plazos, en tanto que a los adultos los desincentivara el volver a estudiar al no percibir una correspondencia positiva entre un aumento del nivel educativo y una recompensa económica, además de que no siempre contaban con el apoyo familiar y laboral para volver a las aulas educativas, lo cual discrepó completamente de los resultados en países como Estados Unidos, pues al contar con un sistema de inversión en capital humano difuso es más común que las personas adultas vuelvan a las escuelas para continuar superándose educativamente (Brinton, 1993).

Se esperaba que aquellos que estuvieran realizando trabajos, remunerados o no, tendrían una menor probabilidad de reincorporarse al sistema escolar en comparación con quienes no realizaban este tipo de actividades, ya que habría un costo de oportunidad relacionado con dejar de percibir ingresos por concepto de su trabajo a cambio de dedicarle tiempo a los estudios. Los resultados mostraron que no existe una asociación estadísticamente significativa entre la actividad previa y el retorno educativo.

Por otra parte y tal como se esperaba, la población urbana, al contar con más oportunidades educativas debido a la existencia de un abanico amplio de escuelas, sistemas y niveles educativos públicos y privados que atienden a personas adultas que trabajan y tienen respon- 
sabilidades familiares, y al hallarse en áreas con más oportunidades laborales para quienes cuentan con mejores niveles educativos, fue quien presentó un mayor riesgo de volver a la escuela en comparación con la población rural, la cual no goza de las mismas oportunidades y estímulos al reintegrarse al sistema escolar.

El reto que en la actualidad México tendría que asumir es el de nivelar tanto en el campo como en la ciudad las posibilidades y las recompensas que se generan al lograr mayores niveles educativos, ya que de no hacerlo, las diferencias escolares entre ambas zonas continuarán siendo abismales, y se sumará esta desventaja a los demás indicadores de rezago educativo que desde siempre han caracterizado a las áreas rurales.

Los orígenes familiares influyen no sólo durante la niñez y adolescencia, sino en los logros laborales y educativos a lo largo de la vida. Las personas que tuvieron padres profesionistas o que realizaban actividades no manuales cuando los entrevistados tenían 15 años tuvieron mayores probabilidades de seguir incrementando su escolaridad en distintos periodos de su vida, en comparación con aquellos que tuvieron padres que desempeñaban actividades manuales, ya sea agropecuarias o no agropecuarias. Esto indica la interdependencia existente entre el estatus ocupacional de los padres y la motivación educativa de los hijos, que tienden a igualarlos o superarlos educativa y laboralmente. Asimismo denota que los hijos se amoldan a las expectativas de los progenitores y que el efecto es duradero en el tiempo.

En relación con el estado civil se precisó que las personas que carecían de algún compromiso conyugal un año antes de regresar a la escuela, ya sea porque eran solteras, divorciadas o separadas, fueron quienes mayores probabilidades tuvieron de reinscribirse en el sistema escolar en comparación con los casados; no se presentaron diferencias por género, lo que vino a confirmar la hipótesis planteada al respecto y también muestra que hay incompatibilidad de roles entre el ser estudiante y estar casado, y que es similar en hombres y mujeres.

Aunado a lo anterior, se esperaba que la asociación negativa más fuerte se presentara entre aquellos que ya tenían hijos, dado que su crianza implica inversiones en tiempo y dinero en detrimento de otras actividades, principalmente entre las mujeres, quienes verían fuertemente limitadas sus probabilidades de retomar sus estudios al tener que dedicar su tiempo, energía y recursos económicos a la crianza de sus hijos. Sin embargo esta variable y su interacción con el sexo no mostraron una relación estadísticamente significativa, por lo que tener 
hijos no parece ser un factor que afecte esta transición. Es posible que esta variable no fuera significativa debido a que está fuertemente asociada con la unión conyugal.

Conforme avanzó el siglo pasado, en el país se fueron construyendo más centros educativos y se ampliaron las opciones escolares, abarcando cada vez a un mayor número de personas. Dado que las tres cohortes analizadas representan distintos momentos históricos del México del siglo Xx y sintetizan en sí mismas los cambios ocurridos en los ámbitos educativo, laboral y económico, se esperaba que las cohortes más jóvenes tuvieran un mayor riesgo de regresar a estudiar beneficiándose así de los logros en instalaciones, programas educativos y personal capacitado que el país tendría ya hacia finales del siglo pasado. Los resultados fueron coherentes con esta hipótesis.

Asimismo, en interacción con el sexo se observó que las mujeres de la cohorte antigua tuvieron riesgos mucho menores de regresar a la escuela en comparación con los varones de su misma generación, lo que indica la presencia de desigualdades educativas por género en este sector poblacional tanto al concluir los estudios (ya que en esta cohorte las mujeres dejaron antes la escuela y tuvieron una escolaridad mucho menor que la de los varones), como al intentar regresar a la escuela. Contrario a ello, las mujeres de la cohorte más joven fueron quienes mayores probabilidades tuvieron de regresar a la escuela, comparadas con los hombres de la cohorte antigua.

El regreso escolar puede ser considerado no sólo como una transición escolar, sino como una estrategia de avance socioeconómico y de movilidad educativa, así como un punto de inflexión para aquellos que la viven, ya que contribuye a redireccionar su vida y a plantearse nuevas metas escolares y laborales.

En resumen, el perfil de las personas de estas cohortes que retomaron sus estudios es el siguiente: son hombres y mujeres que mayoritariamente están en edades juveniles, sin compromiso conyugal, con antecedentes escolares mínimos de secundaria y experiencia migratoria previa, ubicados en áreas urbanas, con padres profesionistas o que desempeñaron actividades no manuales cuando los encuestados eran adolescentes y pertenecientes a las cohortes más jóvenes. Si bien en términos generales en esta transición no se reportan brechas de género al momento de reincorporarse a la escuela, ciertos factores como el pertenecer a la cohorte antigua, fueron elementos que jugaron en contra de la población femenina, mientras que pertenecer a la cohorte más joven posibilitó a las mujeres volver a la escuela. Finalmente, 
quienes habían dejado por segunda vez la escuela tuvieron mayores probabilidades de regresar a la misma en comparación con quienes sólo la habían dejado una vez.

\section{Bibliografía}

Aboites Aguilar, Luis (2006), "El último tramo, 1929-2000", en Pablo Escalante Gonzalbo et al., Nueva historia mínima de México, México, El Colegio de México, pp. 262-302.

Allison, Paul D. (1984), Event History Analysis, Newbury Park-Londres, Sage.

Astone, Nan Marie, Robert Schoen, Margaret Ensminger y Kendra Rothert (2000), "School Reentry in Early Adulthood: The Case of Inner-City African Americans", Sociology of Education, vol. 73, pp. 133-154.

Becker, Gary S. (1981), A Treatise on the Family, Cambridge, Harvard University Press.

Berkove, Gail Feldman (1979), "Perceptions of Husband Support by Returning Women Students”, The Family Coordinator, vol. 28, núm. 4, pp. 541-457.

Blanco, Mercedes (2001), "Trayectorias laborales y cambio generacional: mujeres de sectores medios en la Ciudad de México”, Revista Mexicana de Sociología, vol. 63, núm. 2, pp. 91-111.

Blanco, Mercedes (2002), "Trabajo y familia: entrelazamiento de trayectorias vitales”, Estudios Demográficos y Urbanos, vol. 17, núm. 3, pp.447-483. Disponible en: <www.redalyc.org/articuloBasic.oa?id=31205101 $>$ y $<$ www.jstor. org/stable/40315127>.

Bradburn, Ellen M., Phyllis Moen y Donna Dempster-McClain (1995), "Women's Return to School Following the Transition to Motherhood", Social Forces, vol. 73, núm. 4, pp. 1517-1551.

Brinton, Mary C. (1993), Women and the Economic Miracle, Berkeley, University of California Press.

Camarena C., Rosa María (2000), "Familia y educación en México", en Conapo, La población de México, situación actual y desafíos futuros, México, Consejo Nacional de Población, pp. 233-280.

Card, David (1999), "The Causal Effect of Education on Earnings", en Orley Ashen y David Card (coords.), Handbook of Labor Economics, vol. 3, Amsterdam, Elsevier.

Carranza Palacios, José Antonio (2004), 100 años de educación en México 19002000, México, Noriega Editores.

Castro Méndez, Nina y Luciana Gandini (2006), "La salida de la escuela y la incorporación al mercado de trabajo de tres cohortes de hombres y mujeres en México", ponencia presentada en el v Congreso Nacional de la Asociación Mexicana de Estudios del Trabajo, "Trabajo y reestructuración: los retos del nuevo siglo”, Oaxtepec, México, 17 a 19 de mayo. 
Coubès, Marie-Laure, María Eugenia Zavala de Cosío y René Zenteno (2005), "Introducción. La Encuesta Demográfica Retrospectiva", en Marie Laure Coubès, María Eugenia Zavala de Cosío y René Zenteno (coords.), Cambio demográfico y social en el México del siglo XX, Tijuana, El Colegio de la Frontera Norte, pp. 11-37.

Coubès, Marie-Laure y René Zenteno (2005), “Transición hacia la vida adulta en el contexto mexicano: una discusión a partir del modelo normativo", en Marie Laure Coubès, María Eugenia Zavala de Cosío y René Zenteno (coords.), Cambio demográfico y social en el México del siglo XX, Tijuana, El Colegio de la Frontera Norte, pp. 453-477.

Dávila León, Óscar (2002), “Biografías y trayectorias juveniles”, Última Década, vol. 17, pp. 97-116.

Durán, Jorge A. y Graciela Díaz Hernández (1999), “Análisis de la deserción estudiantil en la Universidad Autónoma Metropolitana”, Revista de la Educación Superior, núm. 74, pp. 1-18.

Echarri Cánovas, Carlos Javier y Julieta Pérez Amador (2007), "En tránsito hacia la adultez: eventos en el curso de vida de los jóvenes en México", Estudios Demográficos y Urbanos, vol. 22, núm. 1 (46), pp. 43-47. Disponible en: $<$ www.redalyc.org/articulo.oa?id=31222103 $>$ y $<$ www.jstor.org/stable / 40315299>.

Eder (1998), Encuesta Demográfica Retrospectiva, México, Instituto Nacional de Estadística, Geografía e Informática.

Elder, Glen H. Jr. (1975), “Age Differentiation and the Life Course”, Annual Review of Sociology, vol. 1, pp. 165-190.

Elder, Glen H. Jr. (1985), "Perspectives on the Life Course”, en Glen H. Elder, Jr. (coord.), Life Course Dynamics: Trajectories and Transitions, 1968-1980, Ithaca-Londres, Cornell University Press, pp. 23-49.

Elder, Glen H. Jr., Monica Kirkpatrick Johnson y Robert Crosnoe (2003), “The Emergence and Development of Life Course Theory”, en Jeylan T. Mortimer y Michael J.S. Hanahan (coords.), Handbook of the Life Course, Nueva York, Kluwer Academic / Plenum Publishers, pp. 3-19.

Elder, Glen H. Jr. y Angela M. O'Rand (1995), “Adult Lives in a Changing Society”, en K.S. Cook, G. Alan Fine y J.S. House (comps.), Sociological Perspective on Social Psychology, Massachusetts, Allyn and Bacon, pp. 452-475.

Felmlee, Diane H. (1988), "Returning to School and Women's Occupational Attainment”, American Sociological Association, vol. 61, núm. 1, pp. 29-41.

Giorguli, Silvia (2002), "Estructuras familiares y oportunidades educativas de los niños y niñas en México”, Estudios Demográficos y Urbanos, vol. 17, núm. 3, pp. 523-546. Disponible en: <www.jstor.org/stable/40315129> y <www. redalyc.org/articulo.oa?id=31205103>.

Giorguli, Silvia (2006), "Deserción escolar, trabajo adolescente y estructuras familiares en México”, en José Luis Lezama y José Morelos (coords.), Población, ciudad y medio ambiente en el México contemporáneo, México, El Colegio de México, pp. 235-274. 
Greaves, Cecilia (2011), "La búsqueda de la modernidad", en Dorothy Tanck de Estrada (coord.), La educación en México, México, El Colegio de México, pp.188-216.

Guerra Ramírez, María Irene (2008), "Trayectorias escolares y laborales de jóvenes de sectores populares. Un abordaje biográfico”, tesis de doctorado, México, Instituto Politécnico Nacional.

Hostetler, Yrew J. (2008), "Educational Careers, Returning to School and WorkFamily Concerns", Filadelfia, Work and Family Researches Network $<$ http://wfnetwork.bc.edu/encyclopedia_entry.php?id=13171\&area=All $>$.

Hostetler, Yrew J., Stephen Sweet y Phyllis Moen (2007), "Gendered Career Paths: A Life Course Perspective on Returning to School”, Sex Roles, vol. 56, núm. 85, pp. 85-103.

Kirby, Peter G., Joan L. Biever, Isaac G. Martínez y John P. Gómez (2004), "Adults Returning to School: The Impact on Family and Work", The Journal of Psychology, vol. 138, núm. 1, pp. 65-76.

Latapí, Pablo (1965), Educación nacional y opinión pública, México, Centro de Estudios Educativos A.C.

Latapí, Pablo (1973), Mitos y verdades de la educación mexicana 1971-1972. Una opinión independiente, México, Centro de Estudios Educativos A.C.

Lindstrom, David P. y Carlos Brambila Paz (2001), "Alternative Theories of the Relationship of Schooling and Work to Family Formation: Evidence from Mexico", Social Biology, vol. 48, núms. 3-4, pp. 278-297.

Lindstrom, David P. y Adriana López Ramírez (2010), "Pioneros y seguidores: selectividad en diferentes generaciones de migrantes", en Katharine M. Donato et al. (coords.), Salvando fronteras: migración internacional en América Latina y el Caribe, México, Miguel Ángel Porrúa, pp. 51-78.

Marcus, Richard D. (1986), "Earnings and the Decision to Return to School", Economics of Education Review, vol. 5, núm. 3, pp. 309-317.

Mier y Terán Rocha, Marta (2004), "Pobreza y transiciones familiares a la vida adulta en las localidades rurales de la península de Yucatán”, Población y Salud en Mesoamérica (revista electrónica), vol. 2, núm. 1, artículo 5, juliodiciembre <http://ccp.ucr.ac.cr/revista>.

Mier y Terán Rocha, Marta (2007), “Transición a la vida adulta. Experiencias de las jóvenes rurales y urbanas", en Ana María Chávez Galindo et al. (coord.), La salud reproductiva en México. Análisis de la Encuesta Nacional de Salud Reproductiva 2003, México, Secretaría de Salud / Centro Regional de Investigaciones Multidisciplinarias, UNAM, pp. 85-106.

Mier y Terán Rocha, Marta y Cecilia Rabell (2000), "El proceso de escolarización de los niños en México, 1960-1990”, en Conapo, La población de México. Situación actual y desafíos futuros, México, Consejo Nacional de Población, pp. 309-326.

Mier y Terán Rocha, Marta y Cecilia Rabell (2001), "Condiciones de vida de los niños en México, 1960-1995. El entorno familiar, la escolaridad y el trabajo”, en José Gómez de León Cruces y Cecilia Rabell Romero (coords.), 
La población en México. Tendencias y perspectivas sociodemográficas hacia el siglo XXI, México, Consejo Nacional de Población / Fondo de Cultura Económica, pp. 759-834.

Mier y Terán Rocha, Marta y Cecilia Rabell (2002), "Desigualdades en la escolaridad de los niños mexicanos”, Revista Mexicana de Sociología, vol. 64, núm. 3, pp. 63-88.

Mier y Terán Rocha, Marta y Cecilia Rabell (2005), "Cambios en los patrones de corresidencia, la escolaridad y el trabajo de los niños y los jóvenes”, en Marie Laure Coubès, María Eugenia Zavala de Cosío y René Zenteno (coords.), Cambio demográfico y social en el México del siglo XX, Tijuana, El Colegio de la Frontera Norte, pp. 285-329.

Millán Ríos, Valeria (2011), "Egreso y abandono universitario en México. Una contribución del análisis demográfico. UNAM, cohortes 1992-1996”, en Mario Martínez, Silvia Giorguli y Edith Pacheco (coords.), México demográfico. Temas selectos de la investigación contemporánea, México, El Colegio de México, pp. 71-121.

Miller Flores, Dinorah (2007), “Trayectorias escolares universitarias e institucionalización del Pronobes en la UAM, tesis de doctorado, Flacso, México.

Miller Flores, Dinorah (2009), "Perspectiva dinámica de la oportunidad educativa: Trayectorias escolares y eventos biográficos de juventud”, trabajo presentado en el x Congreso Nacional de Investigación Educativa, Veracruz, 21 a 25 de septiembre.

Muñoz García, Humberto y María Herlinda Suárez Zozaya (1994), Perfil educativo de la población mexicana, México, INEGI / CRIM, IIS-UNAM.

Nunes de Almeida, Ana y María Manuel Vieira (2009), "At the Entrance Gate: Students and Biographical Trajectories in the University of Lisbon”, Portuguese Journal of Social Science, vol. 8, núm. 2, pp. 165-176.

Ojeda de la Peña, Norma (1989), El curso de vida familiar de las mujeres mexicanas: un análisis sociodemográfico, México, CRIM-UNAM.

Oliveira, Orlandina de y Minor Mora Salas (2008), "Desigualdades sociales y transición a la adultez en el México contemporáneo”, Papeles de Población, vol. 57 , pp. 117-151.

Oliveira, Orlandina de y Minor Mora Salas (2011), "Las diversas formas de hacerse adulto en México: diferencias de clase y género a principios del siglo XXI", en Ana María Tepichín (coord.), Género en contextos de pobreza, México, Programa Interdisciplinario de Estudios de la Mujer, Centro de Estudios Sociológicos, El Colegio de México, pp. 35-55.

Parker, Susan W. y Carla Pederzini V. (2000), "Género y educación en México", Estudios Demográficos y Urbanos, El Colegio de México, vol. 15, núm. 1 (43), pp. 97-122. Disponible en: <www.jstor.org/stable/40315023> y <www.redalyc. org/articulo.oa?id=31204305>.

Pérez Baleón, Guadalupe Fabiola (2010), “Transiciones y trayectorias de tres cohortes de mexicanos en la segunda mitad del siglo XX. Análisis de las diferencias socioeconómicas y de género de la salida de la escuela, el 
primer trabajo y la primera unión conyugal", tesis de doctorado en Población, México, El Colegio de México.

Pérez Baleón, Guadalupe Fabiola (2012), "Análisis por cohorte, género y estrato socioeconómico de la salida de la escuela”, Estudios Demográficos y Urbanos, vol. 27, núm. 3 (81), pp. 699-737. Disponible en: <www.redalyc. org/articulo.oa?id=31229091004 $>$ y <www.jstor.org/stable $/ 41938430>$.

Polo Arnejo, Rita Elena (1999), "La transición a la edad adulta entre los jóvenes del México urbano”, tesis de maestría en Población, México, Facultad Latinoamericana de Ciencias Sociales.

Postigo, Clemencia Esther Caffe y Mirta Daino de Matteoda (2006), “Trayectorias de vida en la pobreza urbana: Una reconstrucción del sentido de la escuela", Cuadernos de la Facultad de Humanidades y Ciencias Sociales, núm. 30, pp. 63-68.

Quilodrán, Julieta (1996), "Trayectorias de vida: un apoyo para la interpretación de los fenómenos demográficos”, Estudios Sociológicos, vol. 14, núm. 41, pp. 393-416.

Rendón, Teresa y Carlos Salas (1996), "Empleo juvenil en México”, Revista Jóvenes, cuarta época, año 1, núm. 1, pp. 34-45.

Santillán, Laura (2007), "Trayectorias educativas y cotidianeidad: una etnografía del problema de la educación y la experiencia escolar en contextos de desigualdad”, Propuesta Educativa, vol. 30, pp. 125-127.

Settersten Jr., Richard A. (2003), "Age Structuring and the Rhythm of the Life Course”, en Jeylan T. Mortimer y Michael J. Shanahan (coords.), Handbook of the Life Course, Nueva York, Kluwer Academic / Plenum Publishers, pp. 81-97.

Sjaastad, L.A. (1962), "The Costs and Returns of Human Migration”, Journal of Political Economy, vol. 70 (suplemento), pp. 80-93.

Suitor, J. Jill (1987), "Mother-Daughter Relations when Married Daughters Return to School: Effects of Status Similarity", Journal of Marriage and the Family, vol. 49, pp. 435-444.

Suitor, J. Jill (1988), "Husband's Educational Attainment and Support for Wives' Return to School”, Gender and Society, vol. 2, núm. 4, pp. 482-495.

Sweet, Stephen y Phyllis Moen (2007), "Integrating Educational Careers in Work and Family. Women's Return to School and Family Life Quality", Community, Work and Family, vol. 10, núm. 2, pp. 231-250.

Terigi, Flavia (2007), "Los desafíos que plantean las trayectorias escolares", trabajo presentado en el III Foro Latinoamericano de Educación "Jóvenes y docentes. La escuela secundaria en el mundo de hoy”, Fundación Santillana, Buenos Aires, 28 a 30 de mayo.

Thomas, Verónica G. (2001), "Educational Experiences and Transitions of Reentry College Women: Special Considerations for African American Female Students”, Journal of Negro Education, vol. 70, núm. 3, pp. 139-155.

Tinto, Vincent (1975), "La deserción en la educación superior: síntesis de las bases teóricas de las investigaciones recientes”, Review of Educational Research, vol. 45, núm. 1, pp. 89-195. 
Tuirán, Rodolfo (2002), "Transición demográfica, trayectorias de vida y desigualdad social en México: lecciones y opciones”, Papeles de Población, núm. 31, pp. 25-66.

Tuirán, Rodolfo y Elena Zúñiga (2000), Situación actual de la mujer en México. Diagnóstico sociodemográfico, México, Conapo (Documentos Técnicos).

Vázquez, Josefina Zoraida (2011), "Renovación y crisis", en Dorothy Tanck de Estrada (coord.), La educación en México, México, El Colegio de México, pp. 217-243.

Zorrilla, Margarita (2004), "La educación secundaria en México: al filo de su reforma”, REICE, Revista Electrónica Iberoamericana sobre Calidad, Eficacia y Cambio en Educación, vol. 2, núm. 1 <http://www.ice.deusto.es/rinace/ reice/vol2n1/Zorrilla.pdf>.

\section{Acerca de los autores}

Guadalupe Fabiola Pérez Baleón es licenciada en Trabajo Social por la Universidad Nacional Autónoma de México (UNAM), maestra en Demografía y doctora en Estudios de Población por El Colegio de México. En 2010 realizó una estancia doctoral en Brown University. Actualmente realiza un posdoctorado en la Universidad Autónoma Metropolitana, unidad Xochimilco, en la Maestría en Estudios de la Mujer y es profesora de asignatura de la Escuela Nacional de Trabajo Social de la UNAM.

Ha sido lectora de tesis de maestría y doctorado sobre temas de salud sexual y reproductiva y género. Cuenta con ocho publicaciones científicas sobre trayectorias de morbilidad materna y sobre transiciones a la vida adulta y su interrelación con la desigualdad socioeconómica y de género. Es miembro del Sistema Nacional de Investigadores, nivel candidata.

David Lindstrom es doctor en Sociología por la Universidad de Chicago, con especializaciones en Demografía y en Estadística. Es profesor y director del Departamento de Sociología y miembro del Population Studies and Training Center de Brown University. Sus investigaciones se han enfocado en los determinantes y las consecuencias de la migración y la salud reproductiva. Actualmente dirige un proyecto sobre la transición a la adultez en Etiopía. 
